\title{
Non-Axisymmetric Inflatable Pressure Structure (NAIPS) Full-Scale Pressure Test
}

Thomas C. Jones*, William R. Doggett $\dagger$, Jerry E. Warren ${ }^{\ddagger}$, and Judith J. Watson* NASA Langley Research Center, Hampton, VA 23681

\author{
Khadijah I. Shariff ${ }^{\S}$ \\ NASA Johnson Space Center, Houston, TX 77058
}

\author{
Alberto Makino** and Bryan C. Yount $^{\dagger \dagger}$ \\ NASA Ames Research Center, Moffett Field, CA 94035
}

\begin{abstract}
Inflatable space structures have the potential to significantly reduce the required launch volume for large pressure vessels required for exploration applications including habitats, airlocks and tankage. In addition, mass savings can be achieved via the use of high specific strength softgoods materials, and the reduced design penalty from launching the structure in a densely packaged state. Large inclusions however, such as hatches, induce a high mass penalty at the interfaces with the softgoods and in the added rigid structure while reducing the packaging efficiency. A novel, Non-Axisymmetric Inflatable Pressure Structure (NAIPS) was designed and recently tested at NASA Langley Research Center to demonstrate an elongated inflatable architecture that could provide areas of low stress along a principal axis in the surface. These low stress zones will allow the integration of a flexible linear seal that substantially reduces the added mass and volume of a heritage rigid hatch structure. This paper describes the test of the first full-scale engineering demonstration unit (EDU) of the NAIPS geometry and a comparison of the results to finite element analysis.
\end{abstract}

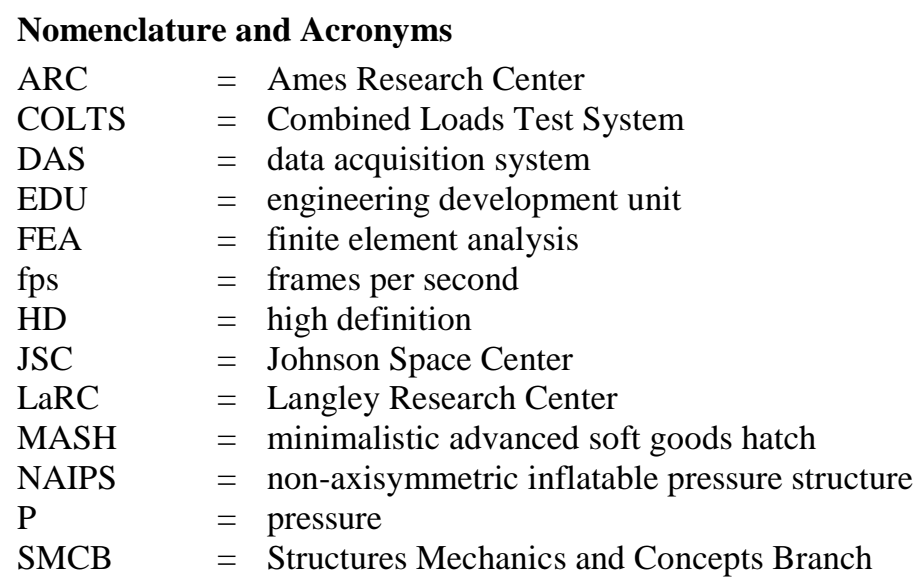

\section{Introduction}

$\mathrm{T}$ HE primary advantage of inflatable space structures is in their ability to be compactly stowed for launch and then subsequently deployed to a much larger operational volume. This packaging also enables the use of smaller launch vehicles or the ability to package multiple inflatable structures on a larger launch vehicle. A secondary

\footnotetext{
${ }^{*}$ Research Engineer, Structural Mechanics and Concepts Branch, M/S 190, AIAA Senior Member

$\dagger$ Research Engineer, Structural Mechanics and Concepts Branch, M/S 190, AIAA Associate Fellow

‡ Research Engineer, Structural Dynamics Branch, M/S 230, AIAA Senior Member

$\S$ Aerospace Engineer, Structural Engineering Division, M/S ES2, AIAA Member

** Structural Analyst, Mechanical Systems and Analysis Branch, M/S 213-4

${ }^{\dagger}$ Aerospace Technologist, Engineering Systems Division, M/S 213-4
} 
advantage is the potential for mass savings due to the use of high-specific strength materials, such as Vectran or Kevlar, and the reduced impact of launch loads on the design due to the initial packaged state. The restraint layer of these softgoods structures consists of a primary layer of webbings or cordage and a secondary layer of fabric. One of the major challenges in softgoods structures is the efficient interfacing of the fabric, webbing and /or cordage with rigid structure in the form of hatches, windows, ports, and other inclusions. Typically, a large mass penalty is induced at these interfaces due to the required terminations of the restraint layer in addition to the mass of the rigid structure itself.

The Non-Axisymmetric Inflatable Pressure Structure (NAIPS) design, detailed in Doggett et $a l^{1}$, provides a geometry that includes several zones of low stress in one principle direction, perpendicular to the primary load paths of the structure (Figure 1). These low principle stresses allow a flexible linear seal to be integrated into the pressure vessel that can replace a typical heritage metallic hatch and its associated interfaces (Figure 2), significantly

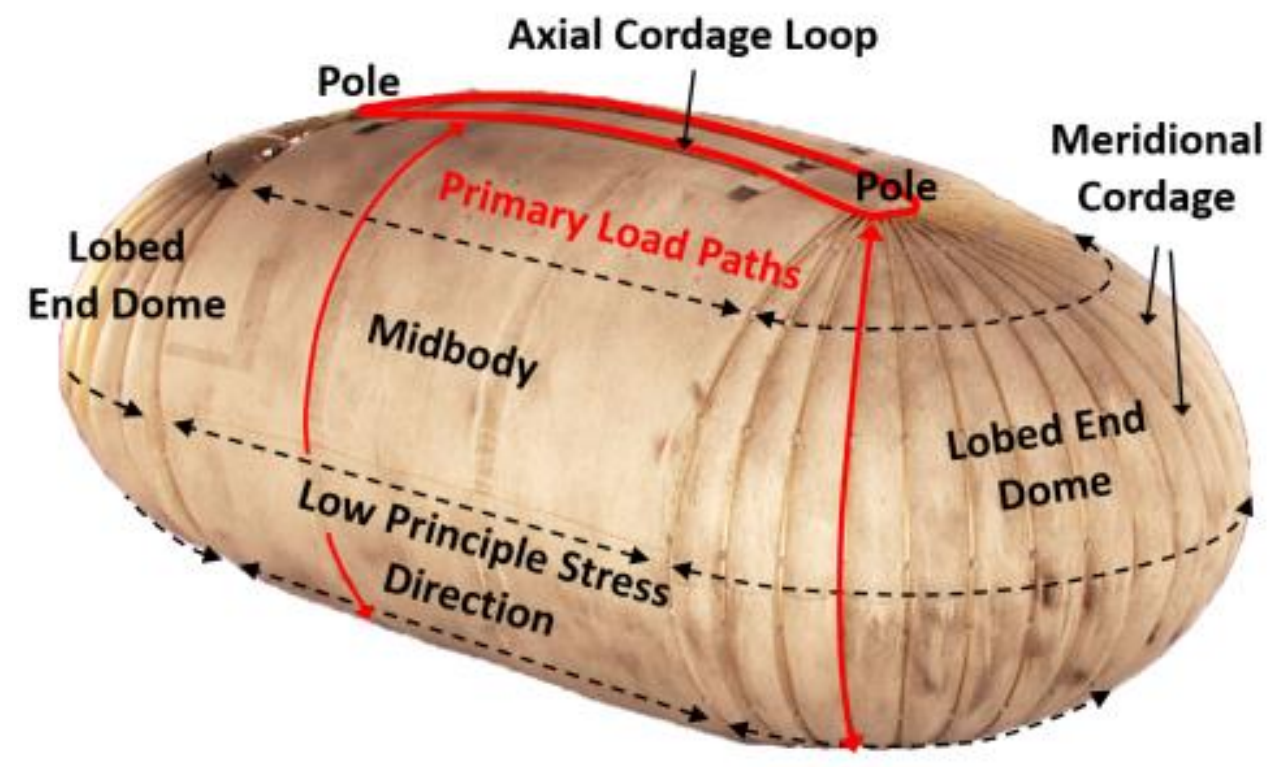

Figure 1. NAIPS design with low stress zones identified (dashed arrow directions).

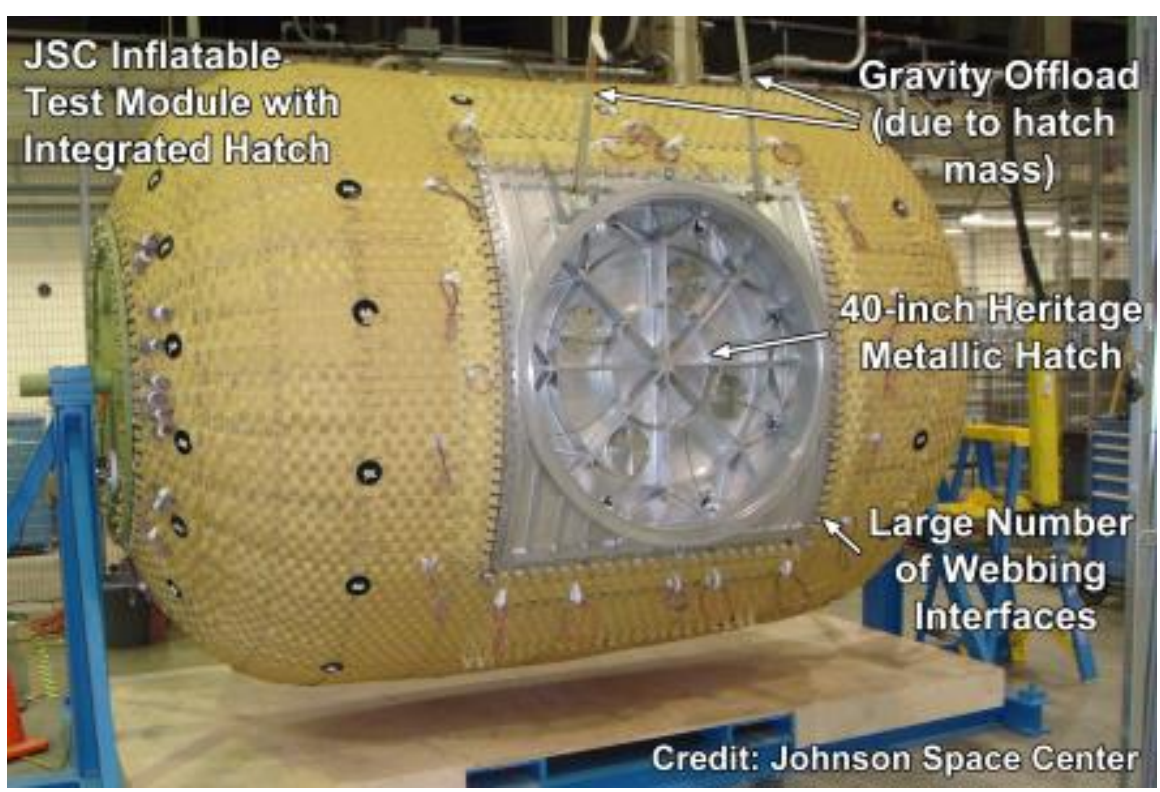

Figure 2. Close woven inflatable with integrated heritage metallic hatch. 
reducing the mass of the structure and increasing its packageability. The principle features of the NAIPS design, that provide the low-stress zones in the structure, are based on previous axisymmetric filamentary inflatables ${ }^{2-6}$ that date back to Taylor's pioneering work on the shape of parachutes ${ }^{2}$. The lobed, low-hoop stress shape used in the end domes of the NAIPS can also be seen in modern army parachutes, drogues, super-pressure balloons, and other more recent enclosed softgoods structures based on the same principles ${ }^{7-8}$. In addition to simplifying the integration of a linear seal opening, the NAIPS design is fabricated in a flat state that simplifies construction versus typical doublycurved inflatables that require precise gores of fabric to be cut and joined to form the desired inflated shape. The primary loads in the end domes are carried through meridional cords that run to two larger axial cordage loops on the top and bottom (Figure 1). These loops carry the loads axially along the midbody, substantially offloading the midbody fabric in the axial direction, which provides another low-stress zone. As the primary load paths are well defined by the cordage that only intersects at the poles, the added indeterminacy of a biaxial load state in the primary restraint layer, as is common in open or closed weave designs, is removed, simplifying the initial analysis and sizing. Softgoods materials are however inherently non-linear and are affected by the addition of stitching and splicing, which impacts the behavior of the finished structure. Finite element analysis (FEA) was therefore used on the initial design sizing to confirm the locations of low stress, determine cordage loads and identify any areas of concern, which informed the final design of a full-scale NAIPS engineering development unit (EDU).

The NAIPS concept also scales well to larger inflatables that could be used, for example, as in-space assembly hangars or large logistics bays on surface habitats where a much bigger opening may be required (Figure 3 ). The loads parallel to the flexible seal are carried by the meridional cordage on each side, while the loads across the lobe are primarily a function of the lobe radius, which can be minimized by design. Scaling a typical rigid hatch up for larger pressure vessels quickly becomes infeasible due to the surface area under pressure, the number of webbing or cordage terminations that would be required (due to the finite width or diameter that can be practicably manufactured), and the shroud size of the launch vehicle, given the inability to package such a large integrated structure efficiently.

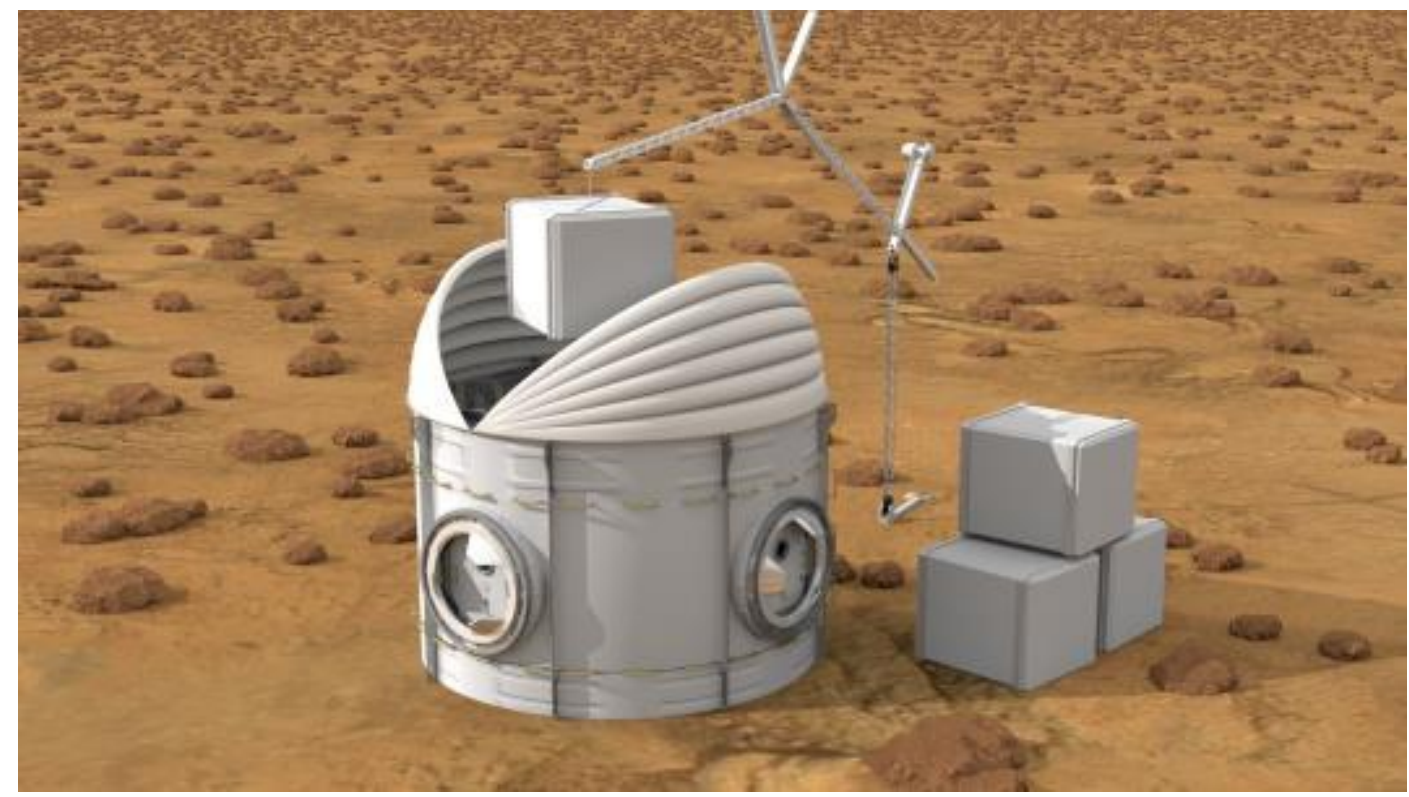

Figure 3. Large inflatable logistics bay on a Mars surface habitat.

The current application and sizing for the NAIPS, under NASA Langley Research Center's (LaRC) Minimalistic Advanced Soft Hatch (MASH) program, is as a two-person airlock (Figure 4) that could be added to an exploration mission architecture and packaged in a variety of ways to minimize its impact on launch volume. The NAIPS EDU fabric shell was fabricated at the NASA Johnson Space Center (JSC) softgoods lab and the cordage was added at LaRC prior to testing at the LaRC Combined Loads Test System (COLTS) Facility. This paper details the design, component softgoods testing, setup and instrumentation, and testing of the full-scale EDU and a comparison of the results with FEA. 


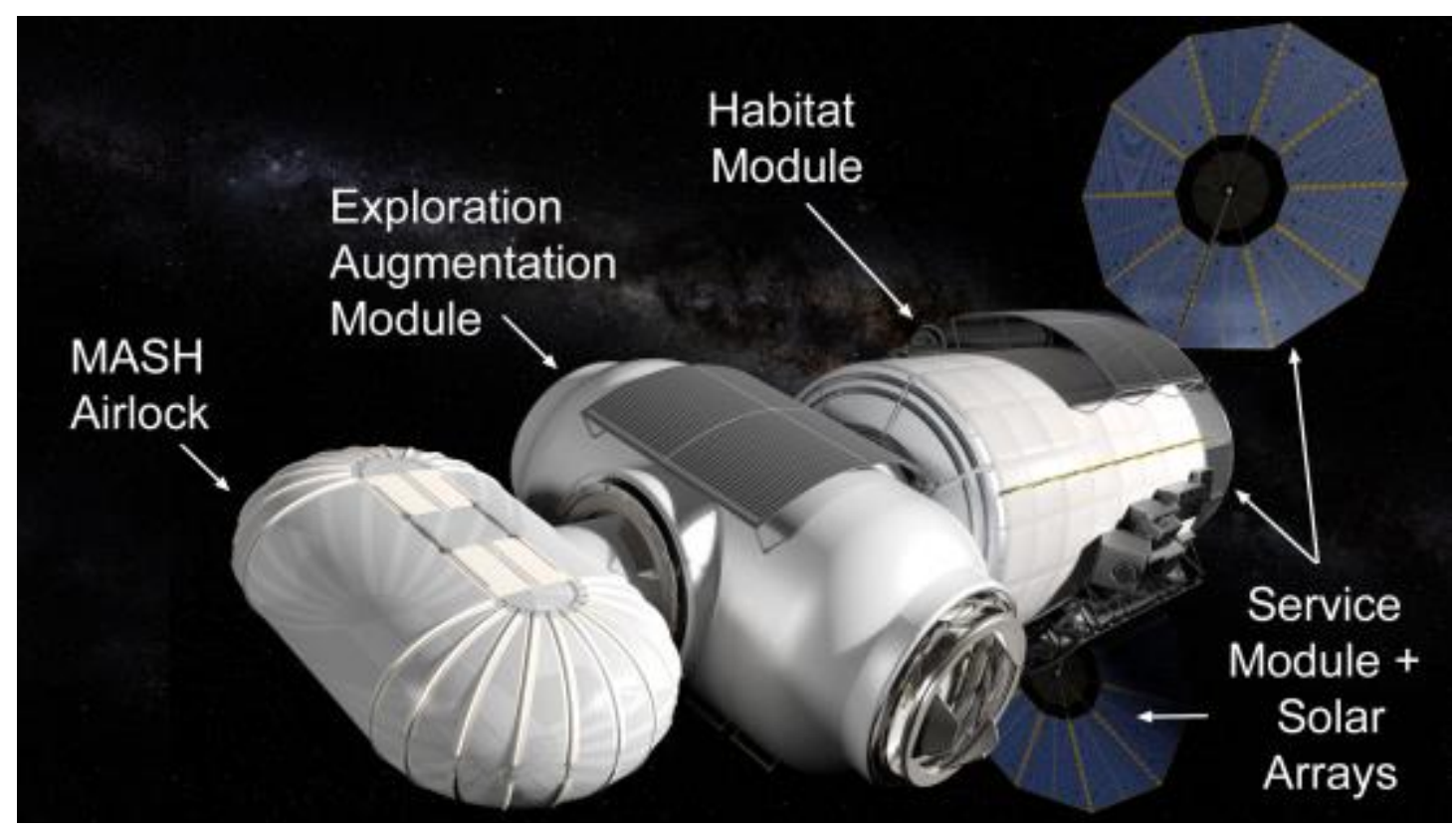

Figure 4. MASH airlock as an element of a NASA exploration architecture.

\section{Test Objectives and Pre-test Research}

The NAIPS design in its embodiment as an airlock has two major design features that require validation in development and testing. The first is the geometry and design of the restraint layer and the second is the flexible linear seal. Under the MASH program, a candidate flexible seal was successfully tested up to $40 \mathrm{psig}$. This paper however focuses on the design and testing of the full-scale NAIPS EDU restraint layer, where the primary objectives are:

- Validate the locations of low stress and compare stains and cordage loads to FEA

- Determine the failure load, mechanism and location for the EDU

- Identify areas of concern for modification in a second generation EDU.

Prior to the design of the EDU, considerable effort was invested into understanding the NAIPS geometry via the construction of a series of sub-scale models of varying complexity; from initial tests with simple polyethylene sheets sealed together and inflated to determine wrinkle zones to a 3/8-scale Kevlar model with cordage (Figure 5). These tests in addition to initial FEA performed at NASA Ames Research Center (ARC) aided in the final design and sizing of the softgoods for the full-scale test article.
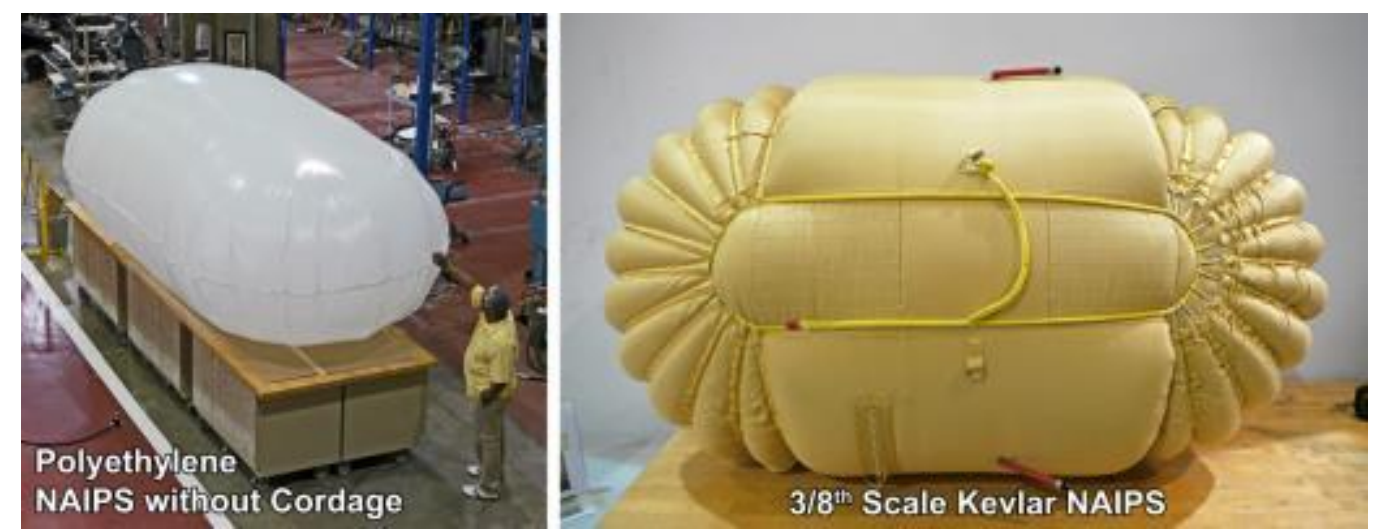

Figure 5. Full and sub-scale models of the NAIPS geometry. 


\section{NAIPS Full-Scale EDU Design}

The NAIPS airlock EDU dimensions were based on providing a suitable volumetric shape in the airlock midbody for two astronauts to don and doff their suits and have additional volume in the domes for ease of ingress and egress from the airlock. The EDU in its initially constructed, flattened state has a total length and width of 204 by 120 inches $(5.2 \mathrm{~m} \times 3.0 \mathrm{~m})$ with a midbody length of 84 inches $(2.1 \mathrm{~m})$, shown in Figure 6a. During fabrication, an additional 1-inch lip around the dome perimeters and a 2.5 -inch lip along each side of the midbody are used to create the seams that attach the top and bottom halves of the article together. The inflated dimensions (Figures $6 \mathrm{~b}$ and $6 \mathrm{c})$ are: length 176.3 inches $(4.5 \mathrm{~m})$, by width 84.4 inches $(2.1 \mathrm{~m})$ at the domes and 80.1 inches $(2.0 \mathrm{~m})$ at the midbody, by depth 67.3 inches $(1.7 \mathrm{~m})$ in the domes and 74.5 inches $(1.9 \mathrm{~m})$ at the center of the midbody. The total volume is $356 \mathrm{ft}^{3}\left(10.1 \mathrm{~m}^{3}\right)$. The article consists of an internal urethane coated Nylon bladder that is oversized by $5 \%$ to unload it in-plane, and a structural restraint layer consisting of Vectran cordage and fabric. The total mass of the as-built EDU without instrumentation was $64.5 \mathrm{lbs}(29.3 \mathrm{~kg})$, which is significantly lighter than current airlock structures. For comparison, the total mass of the International Space Station Quest airlock is 13,369 lbs. Although the Quest mass includes all systems, the structural mass of the NAIPS EDU design is two orders of magnitude lower than the current state-of-the-art rigid airlock.

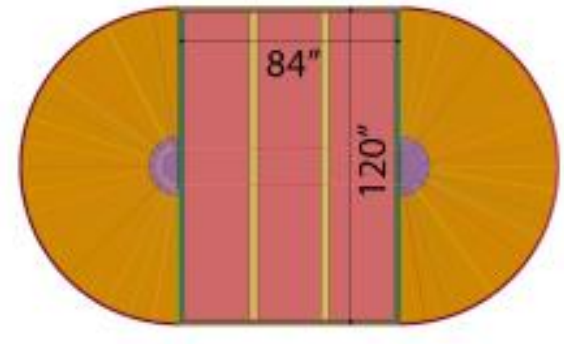

(a) Deflated and flattened.

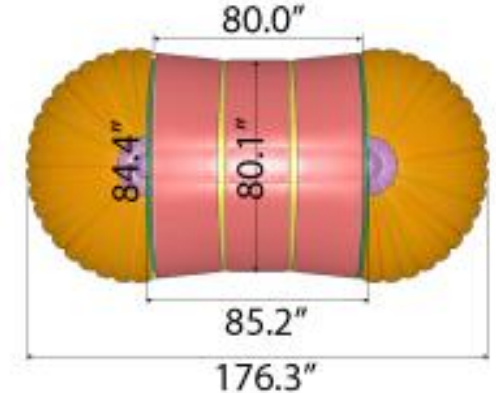

(b) Top view - inflated.

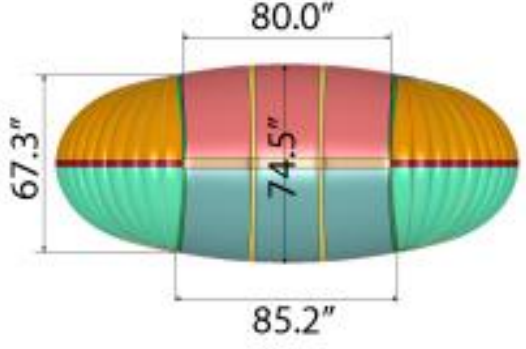

(c) Side view - inflated.

Figure 6. Deflated and inflated NAIPS EDU dimensions.

The structural restraint layer's initial sizing was based on the calculated loads due to an internal pressure of 60.8 psig. However, due to material availability and a desire to focus on the fabric behavior specifically, several components of the restraint layer were oversized for this initial EDU article. The selected internal pressure represents the maximum operating pressure of $15.2 \mathrm{psig}$ (standard atmosphere of $14.7 \mathrm{psig}+0.5 \mathrm{psig}$ overpressure) multiplied by a safety factor of four, as is the current standard for habitable inflatables. The cordage loads are calculated based on the total load due to the maximum pressure ( $60.8 \mathrm{psig}$ ) multiplied by the cross-sectional area of the center of the midbody. This load has to be carried by each set of meridionals on each dome and equilibrated by the two axial cordage loops that transfer the load across the midbody. Twenty-one meridionals were used on each end dome to distribute the load and maintain a calculated, fully developed lobe hoop load of $28 \mathrm{lbs} / \mathrm{in}$ at the operational pressure of $15.2 \mathrm{psig}$. A lobe hoop load of less than $50 \mathrm{lbs} / \mathrm{in}$ was desired for future integration and operation of a flexible seal. The maximum meridional and axial cordage loads were calculated to be $6970 \mathrm{lbs}$ and $139,400 \mathrm{lbs}$, respectively. The selected axial and meridional cordage (Table 1) was intentionally oversized to ensure the failure would occur in the fabric. This was because the focus of this test was on assessing and confirming the low stress zones of the NAIPS geometry up to the burst point. Vectran cordage is manufactured in standard diameters ranging from $1 / 8$ inch up to 4 inches. The 3/8-inch meridional cordage was oversized by two sizes, with a nominal breaking load of 17,500 lbs (1/4 inch and 5/16 inch diameters had nominal breaking loads of 8,000 and $11,700 \mathrm{lbs}$ ). The 1 " axial cordage in a loop configuration was similarly oversized with a nominal breaking load of $220,000 \mathrm{lbs}$ (3/4 inch and 7/8 inch diameters had nominal breaking loads of 137,000 and 185,200 lbs). As can be noted in Table 1, the tested breaking load can vary from the nominal load quoted by the manufacturer, which is discussed in the next section.

The fabrics selected for the EDU are shown in Table 2. A nominally 500x500 lbs/in plain weave Vectran fabric was used in the dome sections, while a nominally $3000 \times 500 \mathrm{lbs} / \mathrm{in}$ bias weave Vectran fabric was used for the midbody. The dome fabric is designed to be offloaded in the meridional direction by the meridional cordage and is 
Table 1. Vectran cordage specifications with manufacturer specified and pristine tested strengths.

\begin{tabular}{|c|c|c|c|}
\hline Braid Type & $\begin{array}{c}\text { Diameter } \\
\text { (in) }\end{array}$ & $\begin{array}{c}\text { Weight } \\
\text { (lbs/in) }\end{array}$ & $\begin{array}{c}\text { Tensile Strength (lbs) } \\
\text { Spec / Pristine Tested }\end{array}$ \\
\hline $\begin{array}{c}\text { Meridional Cords } \\
\text { 12 Strand, Single Braid, } \\
\text { PU Finished Vectran }\end{array}$ & $3 / 8$ & 0.004417 & $17,500 / 19,526$ \\
\hline $\begin{array}{c}\text { Axial Cords } \\
\text { 12 Strand, Single Braid, } \\
\text { PU Finished Vectran }\end{array}$ & 1 & 0.028167 & $110,000 / 88,500$ \\
\hline
\end{tabular}

Table 2. Vectran fabric specifications with manufacturer specified, pristine and preconditioned strengths.

\begin{tabular}{|c|c|c|c|c|c|c|c|}
\hline \multirow{2}{*}{ Weave Type } & \multicolumn{2}{|c|}{$\begin{array}{c}\text { Fiber Denier } \\
\text { /\# of Fibers }\end{array}$} & \multirow{2}{*}{$\begin{array}{c}\text { Width } \\
\text { (in) }\end{array}$} & \multirow{2}{*}{$\begin{array}{c}\text { Weight } \\
\text { (lbs/in }\end{array}$} & \multirow{2}{*}{$\begin{array}{c}\mathbf{t} \\
\text { (in) }\end{array}$} & \multicolumn{2}{|c|}{$\begin{array}{c}\text { Tensile Strength (Ibs/in) } \\
\text { Spec / Pristine / Preconditioned }\end{array}$} \\
\cline { 2 - 3 } \cline { 7 - 8 } & Warp & Weft & & & & Warp & Weft \\
\hline $\begin{array}{c}\text { End Dome Fabric } \\
\text { Plain weave Vectran }\end{array}$ & $\begin{array}{c}200 \\
/ 50\end{array}$ & $\begin{array}{c}200 \\
/ 50\end{array}$ & 62 & 0.000125 & 0.0075 & $500 / 501 / 532$ & $500 / 487 / 501$ \\
\hline $\begin{array}{c}\text { Midbody Fabric } \\
\text { Biased weave Vectran }\end{array}$ & $\begin{array}{c}1500 \\
/ 38\end{array}$ & $\begin{array}{c}1000 \\
/ 11\end{array}$ & 46 & 0.000445 & 0.024 & $\begin{array}{c}3000 / 2810 / \\
2695\end{array}$ & $500 / 620 / 673$ \\
\hline
\end{tabular}

only required to take the low hoop loads in the lobes. The EDU is manufactured in a flat state, with the material laid out orthogonally to the primary axial direction. This requires the use of a balanced, plain weave fabric in the domes to account for the primary load direction changing radially (i.e., in the direction of the meridional cordage). Due to the unconventional geometry, and combination of the lobed, low-hoop stress end domes and cylindrical midbody, there was a need to analytically check the loads in the fabric of the article. Bulging fabric inside the axial cordage loops further complicated the behavior in these regions. FEA, using non-linear material models of the tested pristine fabric, was used to confirm that the maximum loads did not exceed the ultimate strength limits of the tested material. The midbody fabric is naturally aligned with the principle stress directions as constructed and therefore can be customized to take the higher hoop loads in the warp direction and the low axial loads in the weft direction of the fabric. Using a highly biased fabric helps optimize the areal mass of the restraint layer to the loads. In application however, it is prone to windowing (i.e., separation and gapping in the weft fiber direction) and is more challenging to stitch an efficient seam that maintains a high percentage of the fabric strength. In theory, due to wrinkling along the length of the midbody, the weft strength of $500 \mathrm{lbs} / \mathrm{in}$ could be reduced further; however, robustness and manufacturability hinder further optimization.

The EDU design incorporates several additional elements to aid in manufacture, inflation and testing of the article. The broadcloth fabric is custom ordered and can only be manufactured up to maximum widths of about 62inches, therefore for an article of this size multiple pieces of fabric are required to be stitched together to produce the desired inflatable shell. Fell stitch seams were used throughout the article after a series of strength tests were performed at $\mathrm{JSC}^{9}$. The seams and their locations are illustrated in Figure 7. The smaller 2- to 3-inch wide fell seams (A and B) consisted of four or five parallel stitch lines with a Dacron buffer fabric. The larger 5-inch equatorial fell seam (C) included four wider stitch lines with a zigzag stitch, and again used a Dacron buffer layer to better distribute the load through the Vectran fabric. The bladder is internally indexed, via Velcro tabs, to the Vectran fabric restraint layer and the axial cordage is indexed externally also via Velcro tabs to maintain alignment during inflation of the softgoods. The meridional cords were indexed through eight small loops per cord, stitched to the dome fabric. A 30 -inch long linear opening was included under the $5^{\text {th }}$ meridional cord from the midbody on the underside of the article to represent a section of linear seal. The opening was laced closed during the tests to be analogous to a fastened seal. Four 1-inch diameter ports were integrated into the rear end dome. For the tests, two ports were capped and used for expediting low pressure deflation while the other two were used to interface to the 

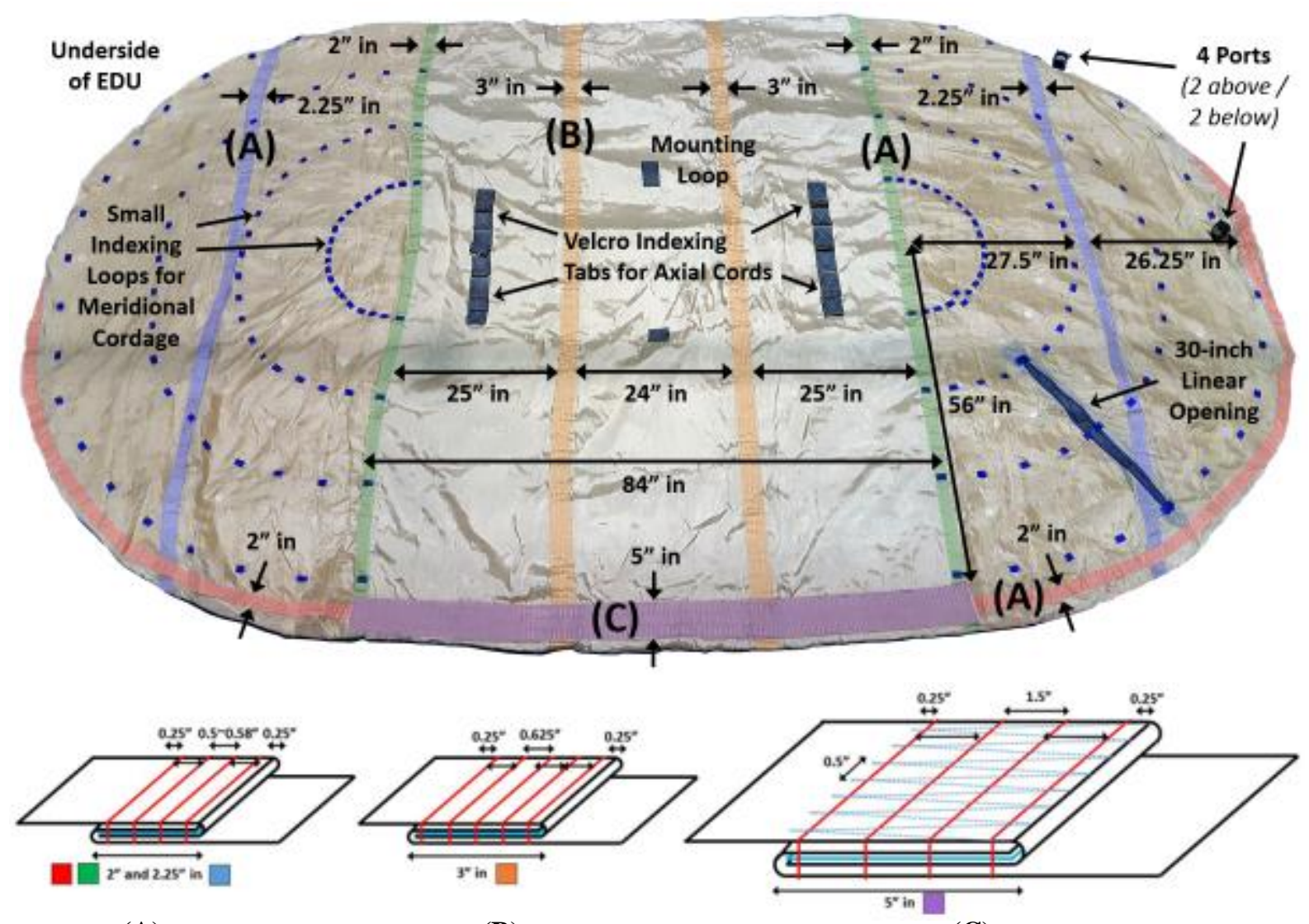

(A)

(B)

(C)

Figure 7. NAIPS EDU fell-stitch seam locations. (A) 4 stitch lines with Dacron buffer (B) 5 stitch lines with Dacron buffer (C) 4 stitch lines and 0.5-inch zig-zag running stitch with Dacron buffer material.

air inlet hose, pressure transducers and an electro-mechanical valve for deflation from pressures greater than 2 psig where personnel were not allowed in the test chamber. Lastly, two heavier stitched mounting loops made from reinforced 500x500 lbs/in Vectran were added on the underside of the article to connect it to a base frame that was itself bolted to the floor of the test chamber.

\section{Vectran Cordage and Fabric Tests}

The cordage and fabric used for the NAIPS EDU are made of Vectran due to its high specific strength and heritage in recent inflatable structures work at NASA and in industry. The Vectran cordage and the broadcloth fabric were tested using load frames at LaRC to determine their ultimate strengths and the load versus strain behaviors to guide the length setting required for the construction of the test article. The cordage displacements were measured using a string potentiometer attached directly to the pin of the pin grips, while the fabric displacements and strains were measured using a stereoscopic photogrammetry system that was also used in the full-scale testing.

\section{$\underline{\text { A. Vectran Meridional and Axial Cordage Tests }}$}

The meridional cords were tested in the same configuration as used for the test article, with loops spliced in at both ends (Figure 8a). A 12-inch end-for-end splice for 12-strand class II (high modulus fiber) rope was used and is designed to provide $90-100 \%$ retention of the pristine cord strength. The loops facilitate the threading of the meridionals on to the axial cordage loop during final construction of the article. A test frame that was long enough to test the required build length of 107.2 inches $(2.7 \mathrm{~m})$ was not available, therefore a series of nine specimens were fabricated at three different lengths $(5,6$, and $7 \mathrm{ft})$ and tested to characterize and generalize the load versus strain curves. Typically, five samples of any specimen type would be preferred but due to time constraints only three were 


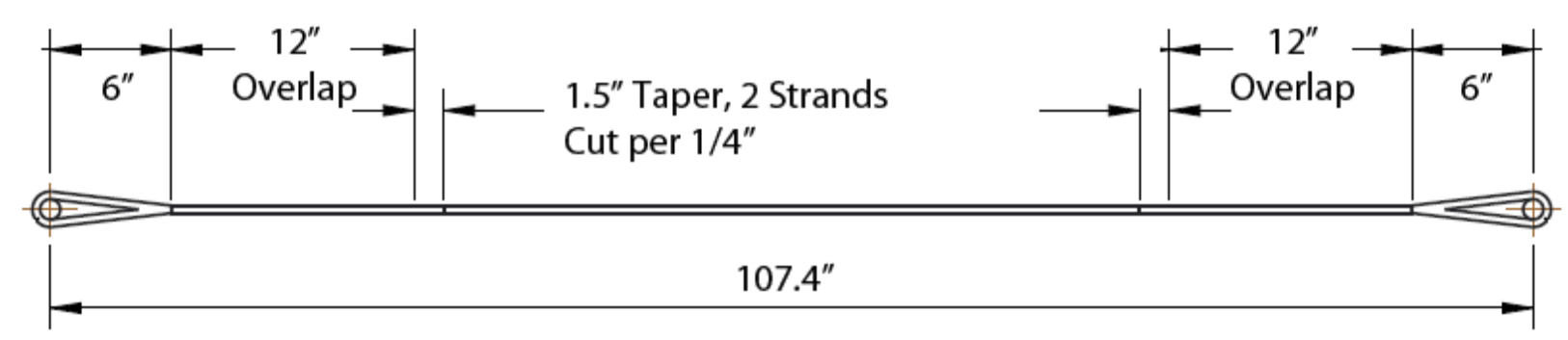

(a) Meridional cord set length and splice dimensions.

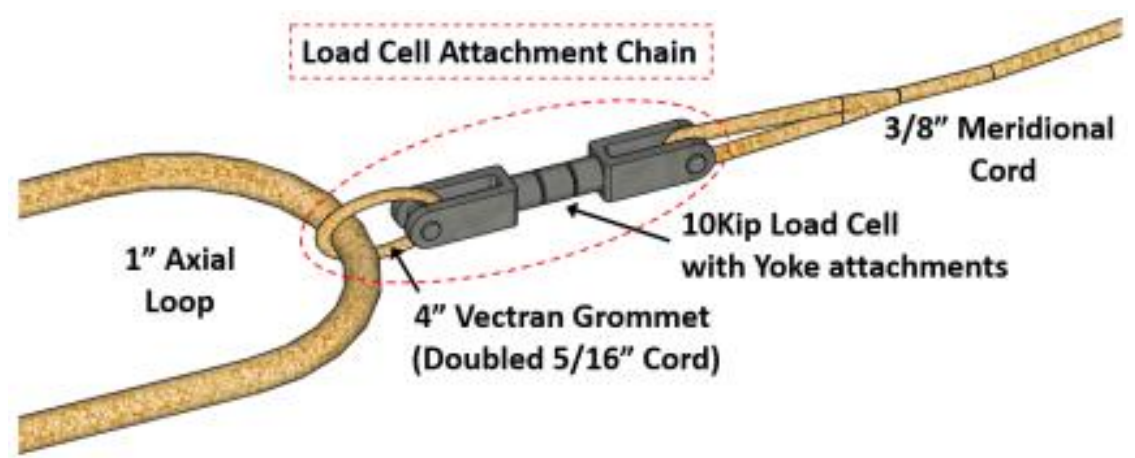

(b) Meridional cord load cell and grommet setup.

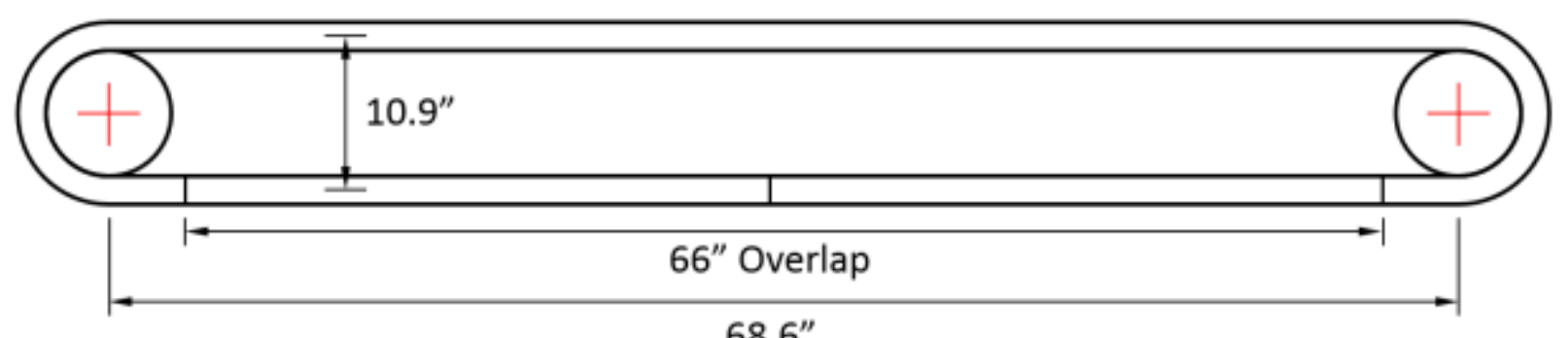

$68.6^{\prime \prime}$

(c) Axial cord set length for final pressurization and test runs 6 to 9.

Figure 8. Meridional and axial cordage as-constructed geometry and load cell / grommet setup.

used for this series. The data for each length were normalized at $300 \mathrm{lbs}$. This is done to reduce the variability between set lengths due to the initial load-up of the fibers at low loads. The $300 \mathrm{lbs}$ preload was also applied during the construction and length setting of the meridional cords for the test article. Figure 9 plots the average load versus strain curves for the three tested lengths and the calculated average curve used to set the build length. The data are shown for the initial ramp up to 10,000 lbs. Ideally, each meridional would be individually characterized and the length would be set based on that cord's data, but as noted that was not possible in this instance. The average breaking strength for all tested samples was $19,526 \mathrm{lbs}$. This is $11.6 \%$ higher than the manufacturer rated 17,500 lbs minimum. Although it is not uncommon for the tested average to be higher than the quoted minimum, it speaks to the efficiency of the splicing method in the tested configuration. The length of the specimens had very little effect on the failure loads, with the averages of each individual length varying a maximum of $1.5 \%$ from the overall average.

In order to monitor the loads in a subset of the article's cordage during the pressure testing, some of the meridionals were sized to incorporate inline load cells. $10 \mathrm{Kip}$ load cells were attached to every other meridional at the bottom of both end domes. Three meridionals were selected to have two load cells attached at both the top and bottom loops, to track load variability along the cords. The load cells were attached between the meridionals and the axial loop cord via a yoke and pin on the meridional side and a yoke and pin with a 4-inch, 5/16" diameter Vectran grommet on the axial side (Figure 8b). The load cell attachment chain, consisting of the yokes, load cell and Vectran grommets, was tested to determine the load-displacement and strain behavior, and this was included in the length setting of the instrumented meridional cords. Due to the short length and high stiffness of the load cell and yokes, 


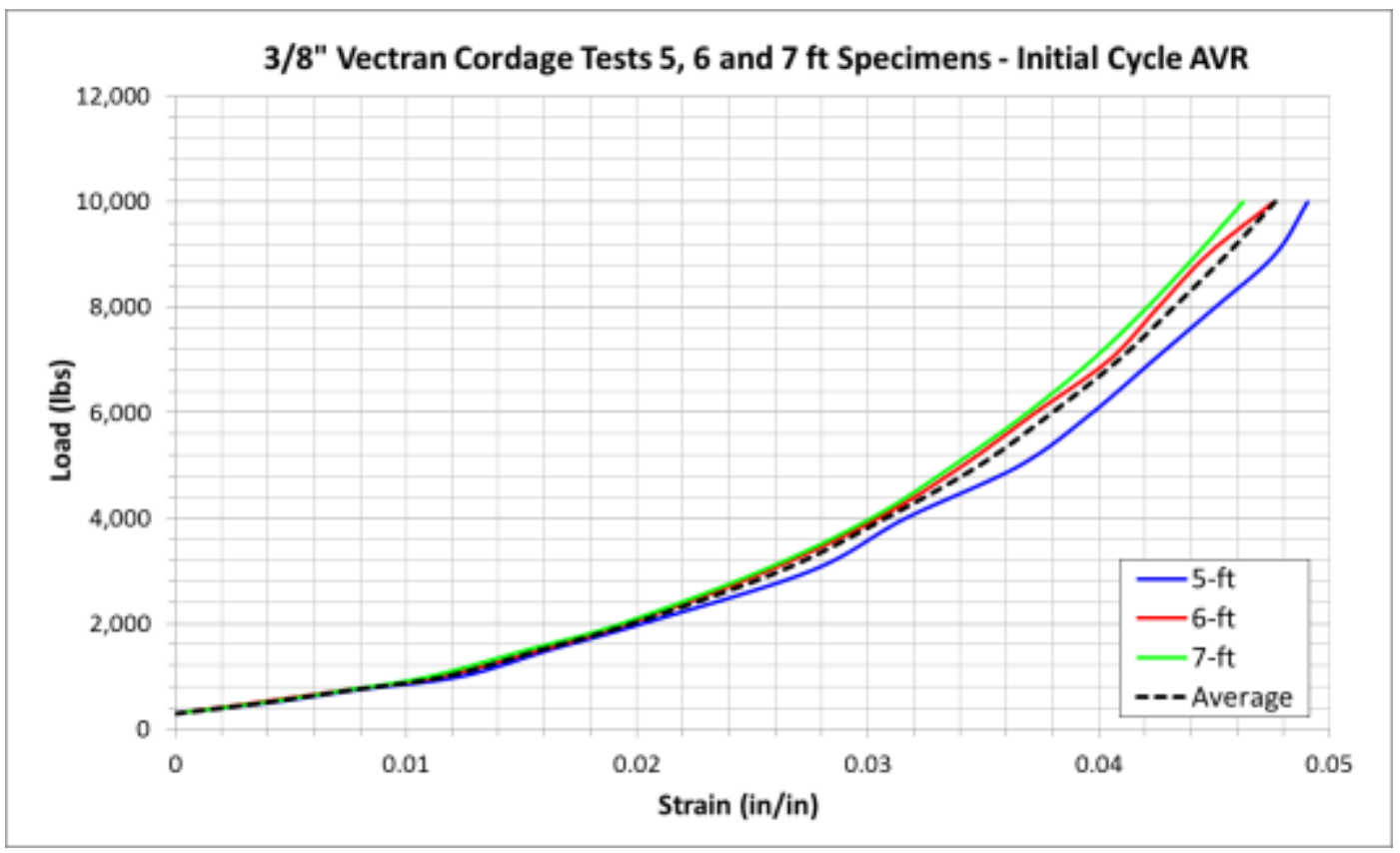

Figure 9. Meridional cordage load versus displacement plots.

the primary cause of variance in the load vs. strain behavior of the meridionals with and without load cells was in the length difference of the cordage section. The shorter cords had stiffer load vs. strain curves, therefore the instrumented cords were set to reach the same length at a specified load level. This load was calculated for a pressure of $30 \mathrm{psig}$, which represented the midpoint of pressurizing the article to $60.8 \mathrm{psig}$.

The axial cords were also tested in a configuration representative of that used in the test article, as a spliced loop (Figure 8c). It was quickly determined that the addition of load cells in the axial cord loops would be too onerous given the required $100 \mathrm{Kip}$ load cell's size and mass, so they were not included in this test. The same end-for-end splice adopted in the meridionals was used but it required a much longer 72-inch overlap length due to the higher tensile strength of the 1-inch diameter cordage. LaRC's 1.2 million-pound load frame in the James Starnes Structures and Materials Lab was used to test the axial cords as it provided the required length and load capacity to accommodate the axial cordage loop specimens. Each of four samples was spliced in the load frame directly around 9.25-inch diameter pin grips to emulate the construction sequence of the actual EDU article whereby the upper and lower axial cords would be fed through the top and bottom loops of the meridional cords and spliced in place. Pin grips are not ideal for testing cordage due to the possibility of high stresses at the contact point between the pin grip and the circular cross-section of the cord, but they were the only option in the required load frame. Several layers of soft terry cloth were used to wrap the grips to provide some stress redistribution and high-speed cameras were used to verify the failure occurred between the tangent points of the grips. The load versus strain curves of the four test specimens are shown in Figure 10, normalized at $1500 \mathrm{lbs}$.

The axial cordage exhibited higher variability in the load versus strain curves than the meridional cordage and therefore the average strain calculated from these data was less reliable for sizing. Higher variance in the 1-inch cordage is in part a generic attribute of increasing the number of fibers in a fiber-based architecture such as a cord or webbing. Higher fiber count increases the chance of local, non-linear fiber interactions, and uneven load up and untwisting or decrimping, which primarily affects the architectural strain variance at low percentages of the ultimate load. It can also produce a higher variance in the breaking strength as well. The average breaking strength of the tested samples was 177,000 lbs (which is equivalent to breaking two sections of 1-inch cordage due to the loop configuration), with all samples within 5\% of the average, or one standard deviation. This average load is $20 \%$ below what would be predicted from the manufacturer's 110,000 lbs rating per single cord multiplied by two. This reduction in the expected load could be for a number of reasons including; lower actual strength in the provided cordage, structural inefficiency in the splice, slippage and uneven load redistribution in the splice or higher stresses than accounted for in the rating due to the use of standard pin grips and a looped configuration. These cordage tests illustrate the need to perform in-house material testing on the final as-used configuration for any softgoods. 


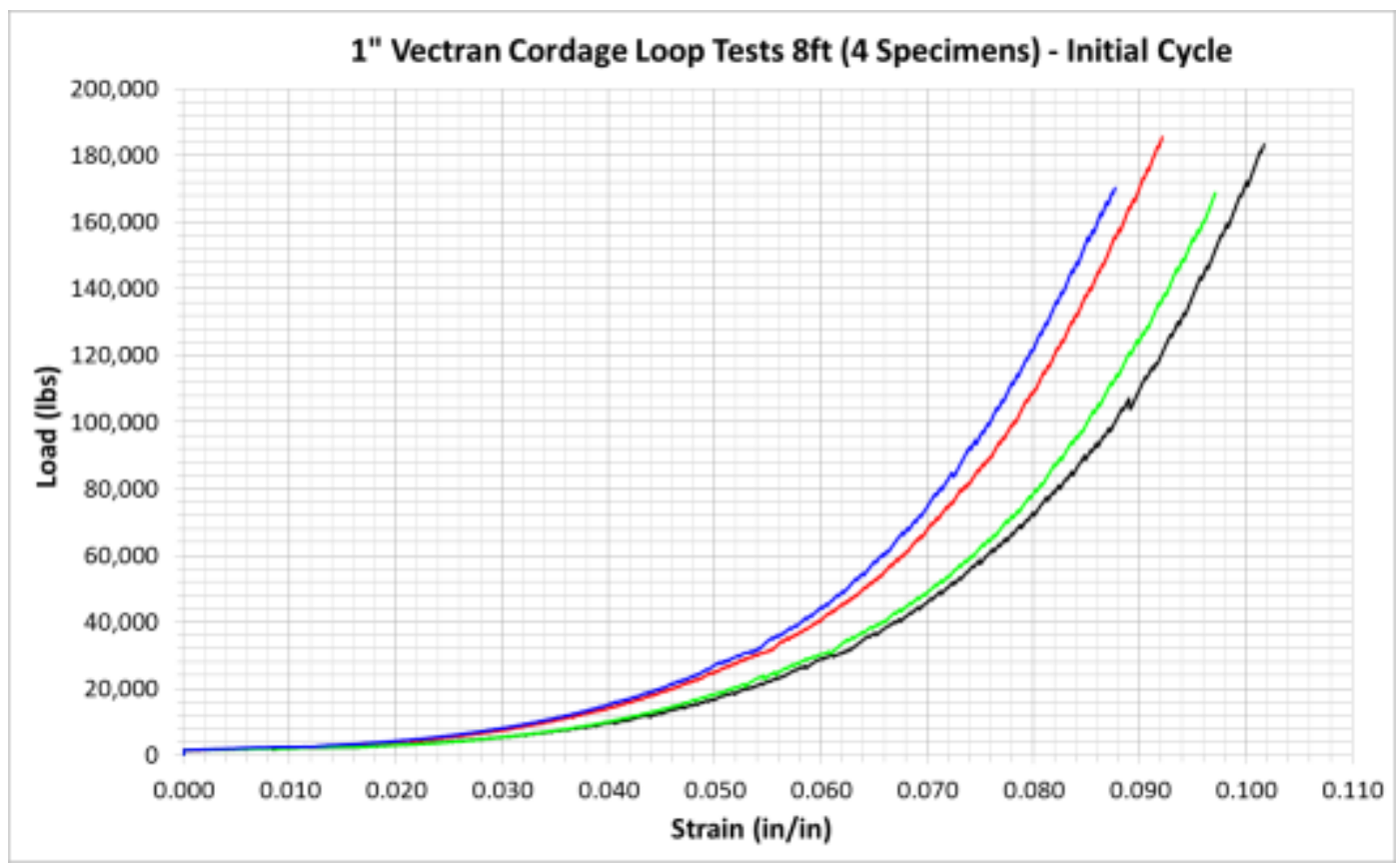

Figure 10. Axial cordage load versus displacement plots.

Preconditioning of the axial cordage, which would aid in reducing the variability in the mechanical behavior, was not possible in the current construction approach due to the axial cord loops being attached during the final assembly of the cordage and fabric shell.

\section{B. Vectran Fabric Tests}

A series of tests were run on the dome and mid-body fabrics to determine their load versus strain response and ultimate tensile strengths in both the warp and weft directions. Two separate sets of tests were performed; the first set, performed prior to the EDU test, loaded the pristine material to failure in a single load-up, the second set of tests, performed after the full-scale test, cycled the tensile load to the levels calculated for the EDU fabrics during its nine pressurization runs. These cycling (preconditioning) tests were performed to better represent the behavior of the fabric in the final test run due to the previous load cycling. Five specimens of each type, for example, cycled - warp direction - dome fabric, were cut from the pristine material, with 40 total samples, 20 pristine and 20 cycled. Each specimen was 60 inches long and 2.5 inches wide (Figure 11), except the mid-body weft direction specimens. They were 46 inches in length, because that was the fabric's manufactured width. A 10-inch long test section was marked on each specimen. Twenty fibers were identified (as per ASTM-5034) ${ }^{10}$ in the direction of loading in the center of

\section{0 in}

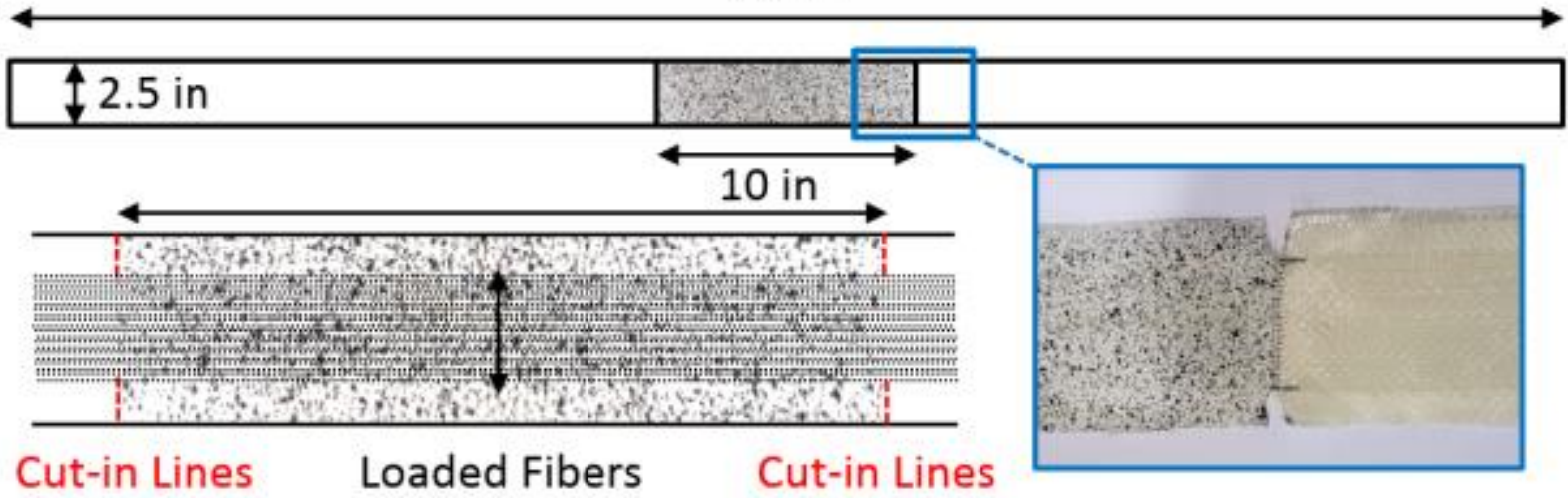

Figure 11. Fabric load test specimen. 
each specimen and cuts were made at the top and bottom of the test section to reduce the loaded fibers down to the selected twenty. The test sections were then speckled with a fine spray paint to apply the random pattern required for photogrammetric strain measurement. Each sample was wrapped on a set of Sedam split-capstan test grips and pulled to failure in a load frame at a rate of $12 \mathrm{in} / \mathrm{min}$. The fabric strains were measured using a stereoscopic photogrammetry system and the load versus strain curves for the warp and weft directions of the two fabrics were plotted for both test sets (Figures 12 and 13).

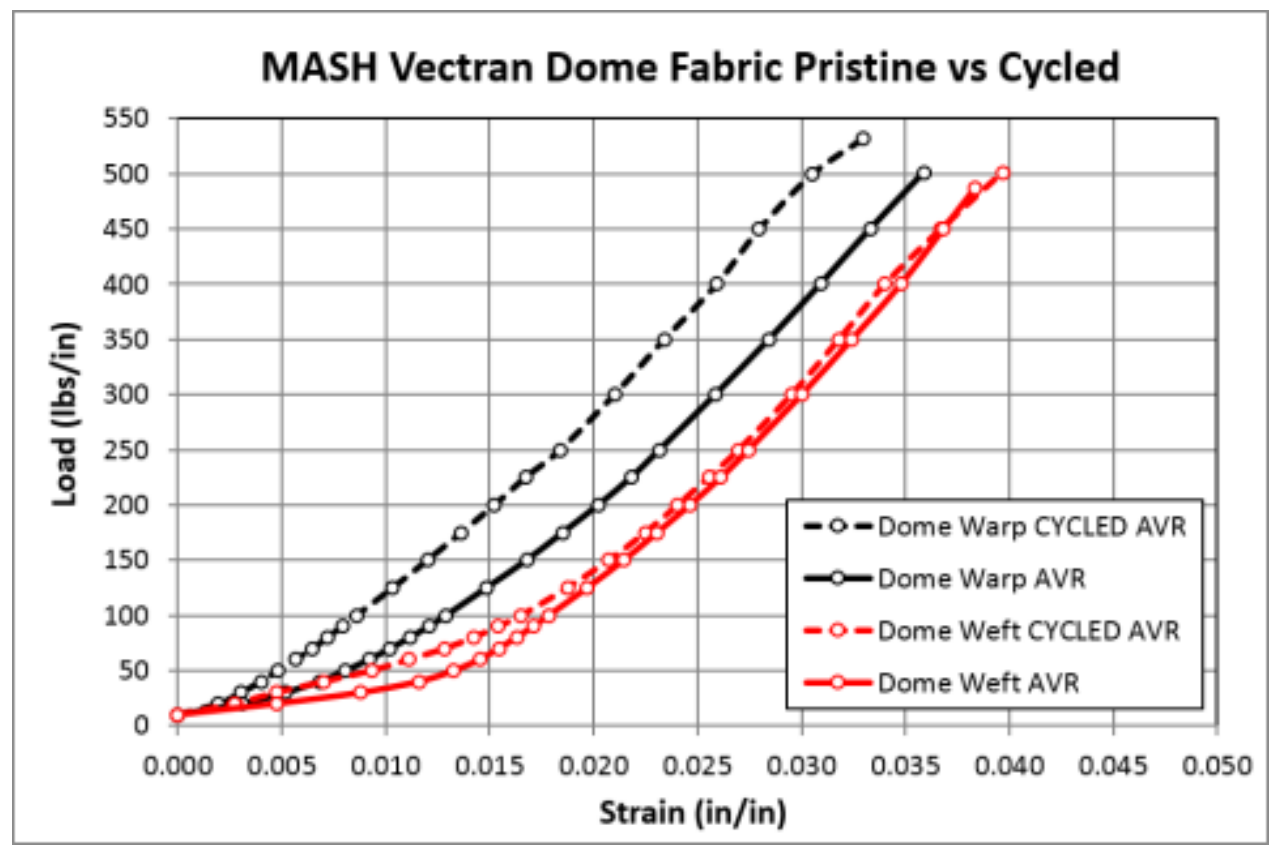

Figure 12. Pristine and preconditioned dome fabric load versus strain plots.

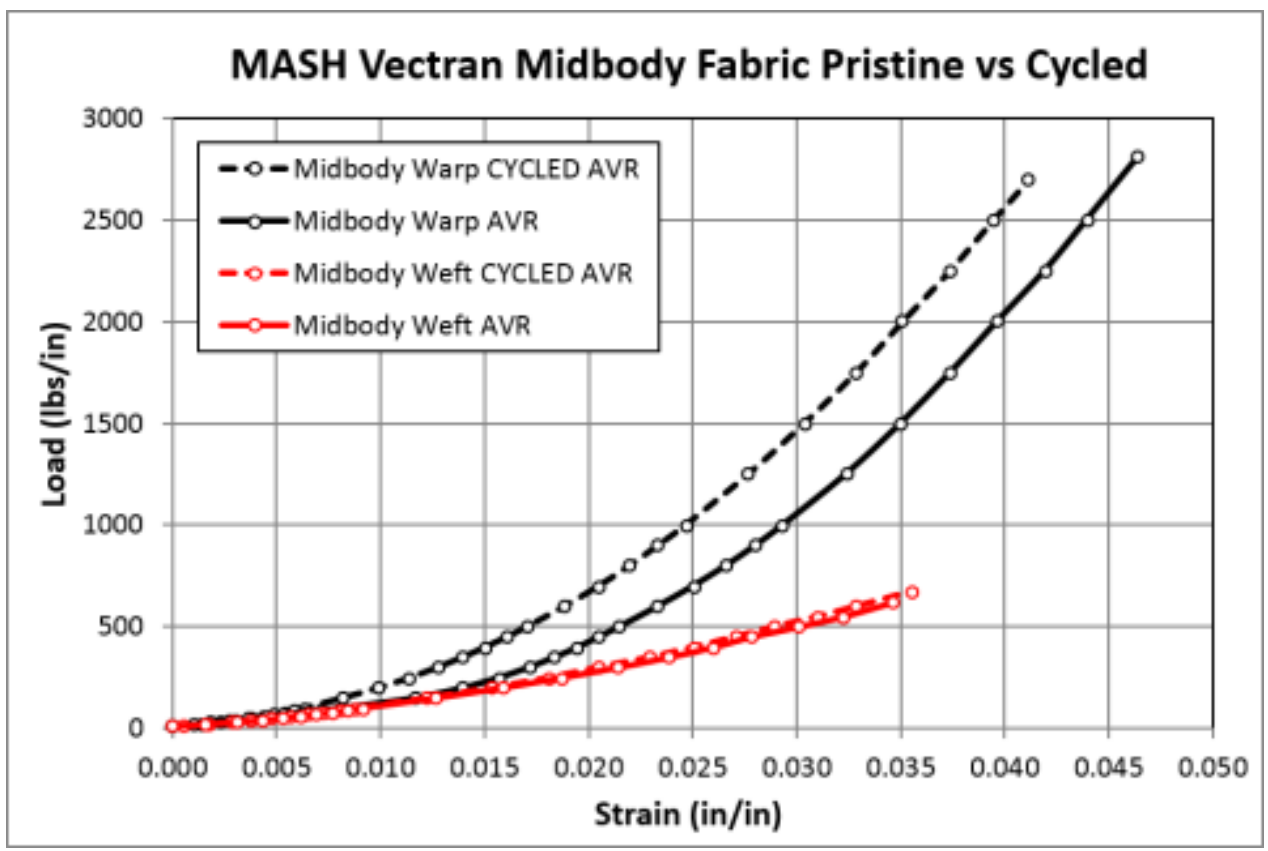

Figure 13. Pristine and preconditioned midbody fabric load versus strain plots. 
The load-cycled fabric tests required determining the loads attained in each pressurization run of the EDU via analysis of the strains from the photogrammetry data in selected portions of the test article. As some areas of the midbody and dome are wrinkled and thus essentially unloaded by design, areas were selected, which represented the high-average strains in the warp and weft directions. This was done to provide the preconditioning loads in the areas of higher stress that were of interest for analysis. To determine the loads for the cyclic fabric tests the following steps were taken; the final pressures for each run were tabulated (Table 3) and the corresponding average strains from the photogrammetry data at those pressures were recorded. The initial strains were calculated from the FEA model from 0 to $0.5 \mathrm{psig}$, as the photogrammetry systems could not track the strains during the initial inflation. The total strains were then converted to nominal fabric loads via the pristine load versus strain plots (solid lines in Figures 12 and 13). The fabric specimens were cyclically loaded to the preload levels calculated for each pressurization run, up to the end of run 8 as shown in the last four columns of Table 3 . A final test is then run on the cycled specimens to represent the final EDU run to failure (dashed lines in Figures 12 and 13). Runs in Table 3 marked with an A or B, designate EDU tests that were held at a specific pressure for five minutes before progressing to the next target pressure.

Table 3. Full-scale EDU pressure test cycles and fabric loads for cycle tests including UTS.

\begin{tabular}{|c|c|c|c|c|c|c|c|c|c|}
\hline \multirow{2}{*}{$\begin{array}{c}\text { Test } \\
\text { Run } \\
\#\end{array}$} & \multirow{2}{*}{$\begin{array}{l}P_{\text {initial }} \\
\text { (Psi) }\end{array}$} & \multirow{2}{*}{$\begin{array}{l}P_{\text {final }} \\
\text { (Psi) }\end{array}$} & \multirow{2}{*}{$\begin{array}{l}\text { Hold } \\
\text { Time } \\
\text { (mins) }\end{array}$} & \multirow{2}{*}{$\begin{array}{l}\text { Total } \\
\text { Time } \\
\text { (mins) }\end{array}$} & \multirow{2}{*}{$\begin{array}{c}\text { Average } \\
\text { Rate } \\
\text { (Psi/min) }\end{array}$} & \multicolumn{2}{|c|}{ Dome Fabric } & \multicolumn{2}{|c|}{ Midbody Fabric } \\
\hline & & & & & & $\begin{array}{c}\text { Warp } \\
\text { (lbf) }\end{array}$ & $\begin{array}{l}\text { Weft } \\
\text { (lbf) }\end{array}$ & $\begin{array}{l}\text { Warp } \\
\text { (Ibf) }\end{array}$ & $\begin{array}{l}\text { Weft } \\
\text { (lbf) }\end{array}$ \\
\hline 1 & 0.0 & 0.5 & $\sim$ & 19.5 & 0.02 & 56 & 15 & 27 & 26 \\
\hline 2 & 0.5 & 1.0 & $\sim$ & 3.2 & 0.17 & 59 & 16 & 34 & 25 \\
\hline 3 & 0.5 & 2.0 & $\sim$ & 6.0 & 0.25 & 67 & 17 & 42 & 23 \\
\hline $4 A$ & 0.5 & 3.0 & 5 & 5.8 & 0.43 & 73 & 18 & 51 & 21 \\
\hline 4B & 3.0 & 5.0 & $\sim$ & 5.5 & 0.49 & 86 & 20 & 67 & 19 \\
\hline 5 & 0.5 & 7.0 & $\sim$ & 14.5 & 0.44 & 100 & 23 & 82 & 19 \\
\hline 6 & 0.5 & 5.0 & $\sim$ & 12.6 & 0.36 & 86 & 20 & 67 & 19 \\
\hline 7 & 0.5 & 2.5 & $\sim$ & 2.3 & 0.69 & 70 & 17 & 46 & 22 \\
\hline $8 \mathrm{~A}$ & 0.5 & 10.0 & 5 & $\sim$ & $\sim$ & 120 & 27 & 102 & 22 \\
\hline 8B & 10.0 & 15.0 & $\sim$ & 38.6 & 0.38 & 162 & 32 & 142 & 34 \\
\hline $9 A$ & 0.5 & 20.0 & 5 & $\sim$ & $\sim$ & 216 & 39 & 198 & 57 \\
\hline $9 B$ & 20.0 & 23.5 & $\sim$ & 35.6 & 0.65 & 252 & 43 & 251 & 80 \\
\hline
\end{tabular}

Preconditioning the samples in this manner is helpful in regards to providing a more accurate material model for FEA than just the pristine sample data, but it has several limitations. The first is that only the pressure versus strain data from the final run were used, as that was the most complete data set, covering the pressures reached by all of the prior runs. Due to the EDU being inflated to different pressure levels during multiple runs, there were different levels of preconditioning applied in every run. Ideally, the loads for the fabric cycling should be extracted for each run and applied to that specific cycle. This would require a separate set of cycling tests for each run to get the correct load versus strain curves for each level of preconditioning. The strain data were not available for every run due to some initial difficulties with the photogrammetry setup so the best data set was used. Therefore, to find the load levels used for the preconditioning cycles, the pristine fabric curve had to be used, which underestimates the load versus the stiffer preconditioned sample. The second consideration is that the fabric is not uniformly stressed due to the geometry of the design, thus different portions of the article saw different levels of preconditioning. Average strains were used to approximate reasonable preconditioning loads but this again is not ideal and illustrates the difficulty in determination of loads in a complex inflatable structure, even one with nominally deterministic primary load paths in the tendons.

\section{Full-Scale NAIPS EDU Setup and Testing}

A major part of the full-scale test, in addition to the sizing, material testing and construction of the article, was 
the setup and instrumentation of the EDU in an appropriate facility. The Combined Loads Test System (COLTS) facility at LaRC was selected as it provides a large-scale structural test chamber that accommodates high pressure and high load test articles (Figure 14) in a steel-reinforced concrete test bay that is $32 \mathrm{ft}$ by $47 \mathrm{ft}$ by $72 \mathrm{ft}$ (9.8 by 14.3 by $21.9 \mathrm{~m}$ ). The facility also had the data acquisition systems and power required for all the sensors, lights, cameras, and other instrumentation.

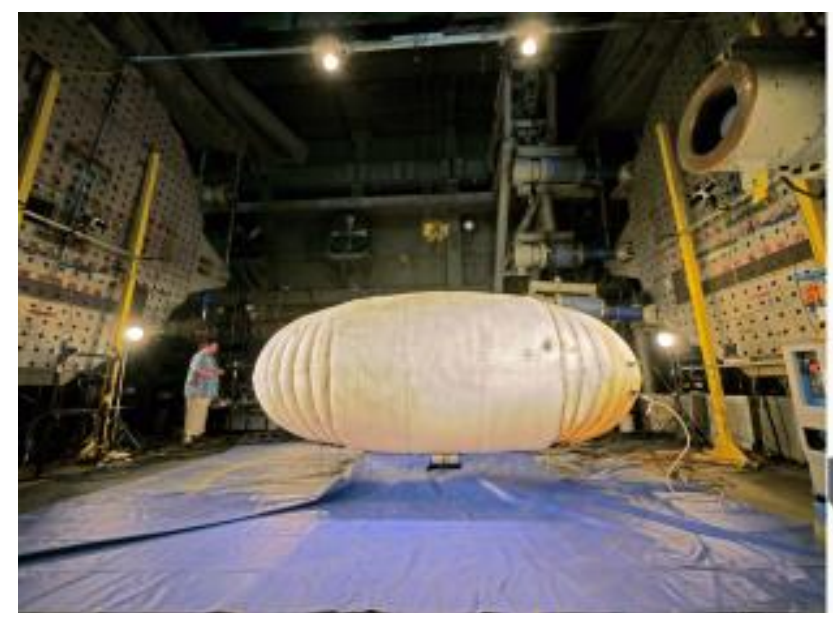

(a) NAIPS EDU in COLTS

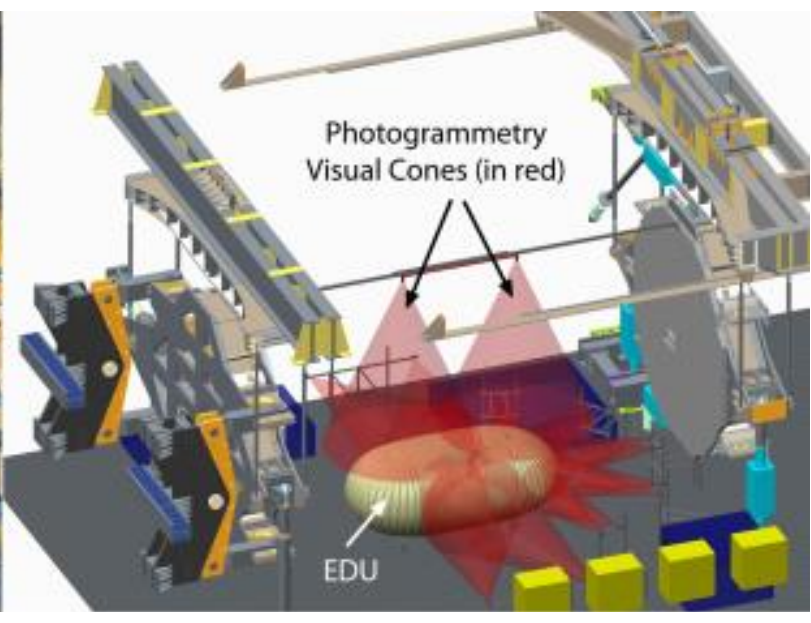

(b) Photogrammetry capture areas on EDU

Figure 14. COLTS test facility with article prior to testing and a computer generated model of COLTS showing visual cones of photogrammetry cameras.

\section{A. Instrumentation, Cameras, and Lights}

The primary goals of the instrumentation suite were, 1) to record a sufficiently detailed data set of the strains in the fabric and the loads in the cordage to compare to FEA and 2) to identify the location and type of failure that occurred at burst. This was accomplished by using the following systems, diagrammed in Figure 15:

- Photogrammetry systems (8 with 2 cameras each) positioned around the front, sides and top of the article to measure full-field strains on the surface (visual frame cones shown in Figure 14 in red). 5 Megapixel (MP) camera systems were used at the front and sides and a 29 MP system was used overhead to overlap with the other 7 systems.

- Load cells (25 at $10 \mathrm{Kip}$ each) attached to every other meridional cord, three of which had load cells on both ends.

- Inlet and outlet pressure transducers, measuring pressure from the air regulator and article.

- High-Definition (HD) real-time video cameras (12) distributed around and above the article, recording to individual digital video recorders.

- High-speed cameras (4) recording at 10,000 fps to 20,000 fps, one on each side, front, rear, left, and right.

As discussed in section IV-A, load cells were only integrated with the meridional cordage due to the size and weight of the load cells that would be required for the high loads in the 1-inch cordage. The data acquisition system (DAS) recorded the two differential pressure channels and the 25 load cell inputs at $10 \mathrm{~Hz}$, and output the article pressure and the first load cell data channels to the photogrammetry system to provide two inputs for post-test data synchronization. The eight photogrammetry systems had a synchronous trigger box that fired all systems at the same time at a rate of $0.5 \mathrm{~Hz}$. A coordinated universal time signal was passed to the DAS and to an overlay board that displayed it on two of the HD video feeds. This was used to synchronize all $12 \mathrm{HD}$ video channels with the recorded data. The high-speed cameras were all connected to a single trigger switch that could be depressed by a member of the team when the burst occurred. These cameras operate in a loop-recording mode that was set to capture approximately the two seconds before and one second after an event trigger. Due to the availability of the high speed cameras, three different models were used that had different levels of capability in terms of resolution and frame rate. The primary requirement met by all was the ability to record at at least $10,000 \mathrm{fps}$ and $640 \times 480$ resolution. 


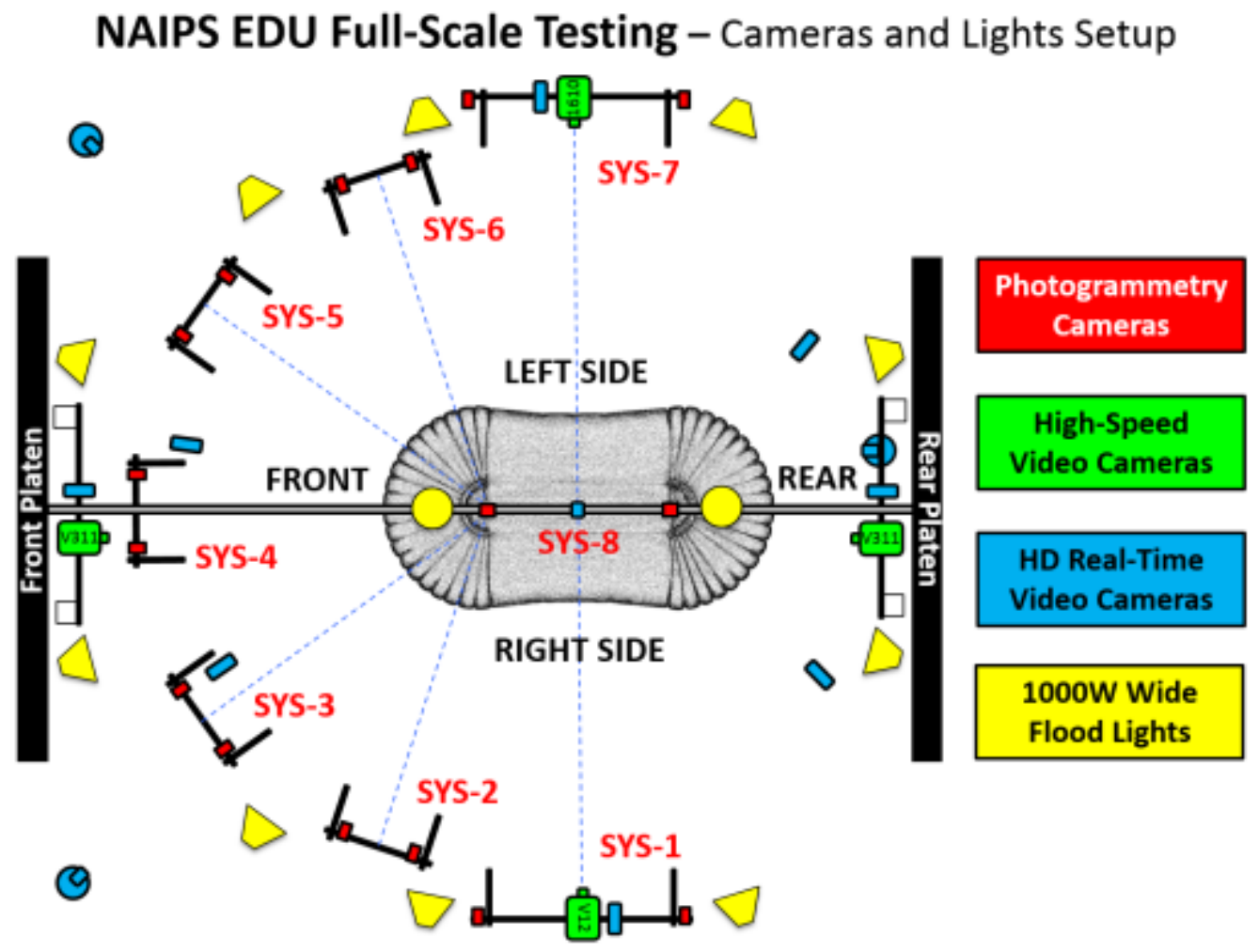

Figure 15. NAIPS EDU cameras and lights setup. Photogrammetry systems SYS-1 to SYS-8 are
emphasized (in red). High-speed cameras, HD cameras and lights are color coded.

The lighting was an additional challenge for this setup, as the high-speed cameras require a significant amount of light to obtain the desired $10,000+$ fps rates, while the photogrammetry cameras and HD cameras require far lower lumens. The final light arrangement consisted of twelve $1000 \mathrm{~W}$ wide-beam halogen floodlights distributed around the perimeter of the article with two of them placed on an overhead beam that also mounted two photogrammetry cameras and an HD video camera. The apertures of all photogrammetry and HD cameras were reduced to accommodate the high brightness level, which as a result also increased the focal depth of the photogrammetry systems. These camera settings were important given the high curvature of the EDU and the need to track the strains as the article inflated.

\section{B. Pressurization System}

The COLTS facility has a high-pressure air system rated to 600 psig with an automatic pressure controller, but it does not provide fine control at low pressures $(<2 \mathrm{psig})$ that was required for these tests. Therefore, the $120 \mathrm{psig}$ shop air supply was used for the EDU pressurization system. The system was run in an open (vented) mode that was controlled manually through a regulator and pressure gauge in an adjacent room to the main test chamber. The inlet supply to the article had an inline solenoid valve to shut off the air supply and hold at a target pressure. A second solenoid valve was connected to another port on the article that could be opened to vent air directly to the test chamber. The other two ports in the EDU were capped and were there as backups and could be used for faster venting once the article was at a pressure below 2 psig where it was deemed safe to enter the test chamber.

\section{Pressurization Test Runs}

The testing of the NAIPS EDU consisted of a series of nine inflations over three days that took the article to progressively higher pressures culminating in failure at 23.5 psig. Each test began with zeroing the load cells and differential pressure transducers with the article deflated. The article was then inflated to a nominal $0.5 \mathrm{psig}$ where a system check of the photogrammetry systems was performed and any systems out of calibration were recalibrated. The initial 0.5 psig pressurization was selected to allow inspection of the module at its nominal geometry prior to 
running each test. Once all systems were ready, the COLTS test bay was cleared of personnel and locked down. The photogrammetry systems were initiated first to make sure they were running and synced, followed by the DAS and cameras systems. The EDU was inflated at between $0.2 \mathrm{psi} / \mathrm{min}$ and $0.8 \mathrm{psi} / \mathrm{min}$, depending on the target pressure.

Test run 1 was the initial slow inflation from 0 to 0.5 psig followed by runs 2 through 5 that took the article to 1 psig, 2 psig, 3 and 5 psig, and 7 psig on the first day of testing without incident. After each run, the article was deflated slowly, via the two solenoid valves attached at the ports, to $0.5 \mathrm{psig}$ and inspected. After the first day's testing, a small amount of windowing in the midbody fabric weft direction was observed near the front end dome / midbody transition, suggesting the axial cords were not fully offloading the fabric down the length of the article. Given the variability seen in the axial cord testing, it was argued that the axial cords were set too long. It was therefore decided to replace the upper and lower axial loops with ones that were fabricated 4 inches shorter to induce greater offloading at each end and reduce the load on the weft fabric in the midbody. A successful checkout test of this new configuration was run on day two to 5 psig (run 6). The third and final day of testing started with run 7 , which was curtailed due to issues with the DAS and photogrammetry systems not recording data properly. After resolving the problems with the instrumentation, run 8 took the article up to 10 psig and then to the operational design pressure of $15 \mathrm{psig}$ with five minute holds at each pressure, before bringing the pressure back down to 0.5 psig. No observable damage was seen after a complete inspection of the article. The final run initially took the test article from 0.5 psig to 20 psig at which point the pressure was held for 5 minutes. Then, during pressurization to 25 psig, the article burst at 23.5 psig.

\section{Test Results and Comparison to FEA}

The failure (shown in Figures 16 and 17) occurred in the midbody fabric weft direction approximately 3/4-inch away from the inside edge of one of the 3-inch midbody hoop seams. The failure of the fabric led to bladder herniation and a rapid unzipping of both the weft fibers adjacent to the initial failure and the bladder itself. The failure propagated in both directions along the hoop seam and was arrested on both sides of the article at the 5-inch midbody equatorial seam. A light colored damage zone became visible 49 seconds prior to the failure of the article and could be seen to grow in the axial direction (weft) up until the burst occurred. The image sequence on the right of Figure 16 shows the damage zone from 1 minute to 1 second prior to failure, and shows the 5 stitch lines in the adjacent seam. The lighter, thicker line to the right of the stitch lines is an unpainted area of the fabric that became exposed as the article inflated. The midbody weft direction strength around the seams was a concern prior to testing the EDU, due to the difficulty found during fabrication of stitching in the weaker direction of the highly biased midbody fabric. These details of the failure event were obtained shortly after the test directly from observing the $\mathrm{HD}$, high-speed and high-resolution camera images. The following sub-sections discuss the results of comparing the load cell and photogrammetry data to a detailed FEA model of the test article in the final run to failure.

\section{A. FEA Modeling Approach}

The characterization of the cordage and fabric behaviors, and the extensive instrumentation of the NAIPS EDU, were undertaken to provide a detailed data set for validation of an FEA model of the article. The model was created using LS-DYNA R.7.0.0, an explicit FE solver. Data for the preconditioned meridional tendons, the axial tendon loops and the preconditioned dome and midbody fabrics were included via non-linear material definitions. The EDU fabric envelope was modeled with tension-only shell elements to which the internal pressure was applied directly. The oversized internal bladder layer was not included in this model. The cordage was modeled with beam elements that used a tension-only elastic cable material definition. The meridional cords are threaded on to the axial cordage via end loops, as in the actual article, and are prevented from disengagement by means of cord-to-cord contact definitions. All cords are independent of the restrain layer, and contact definitions between the cordage and fabric prevents pass-throughs. A coefficient of friction of 0.35 , previously found for Vectran-Vectran contact, is used for all contact definitions. In the EDU, cordage tensioning is achieved by undersizing the cords with respect to the restraint layer. Undersizing the cordage in the FEA model, which has to be inflated from an initially flat state, is achieved by contracting the length of the axial cords via virtual thermal turnbuckles. The axial cords include a section that has a tuned coefficient of thermal expansion that produces a set length (with a $\Delta \mathrm{T}$ ) at a desired pressure, in this case at $10 \mathrm{psig}$. This approach is not a perfect representation of the cordage load up, since the meridional cords that are at an angle with respect to the axial cords, particularly those at 90-degrees, cannot be fully tensioned. Seams are included by adding bands of fabric of the appropriate width and thickness. It was found that the mid- 

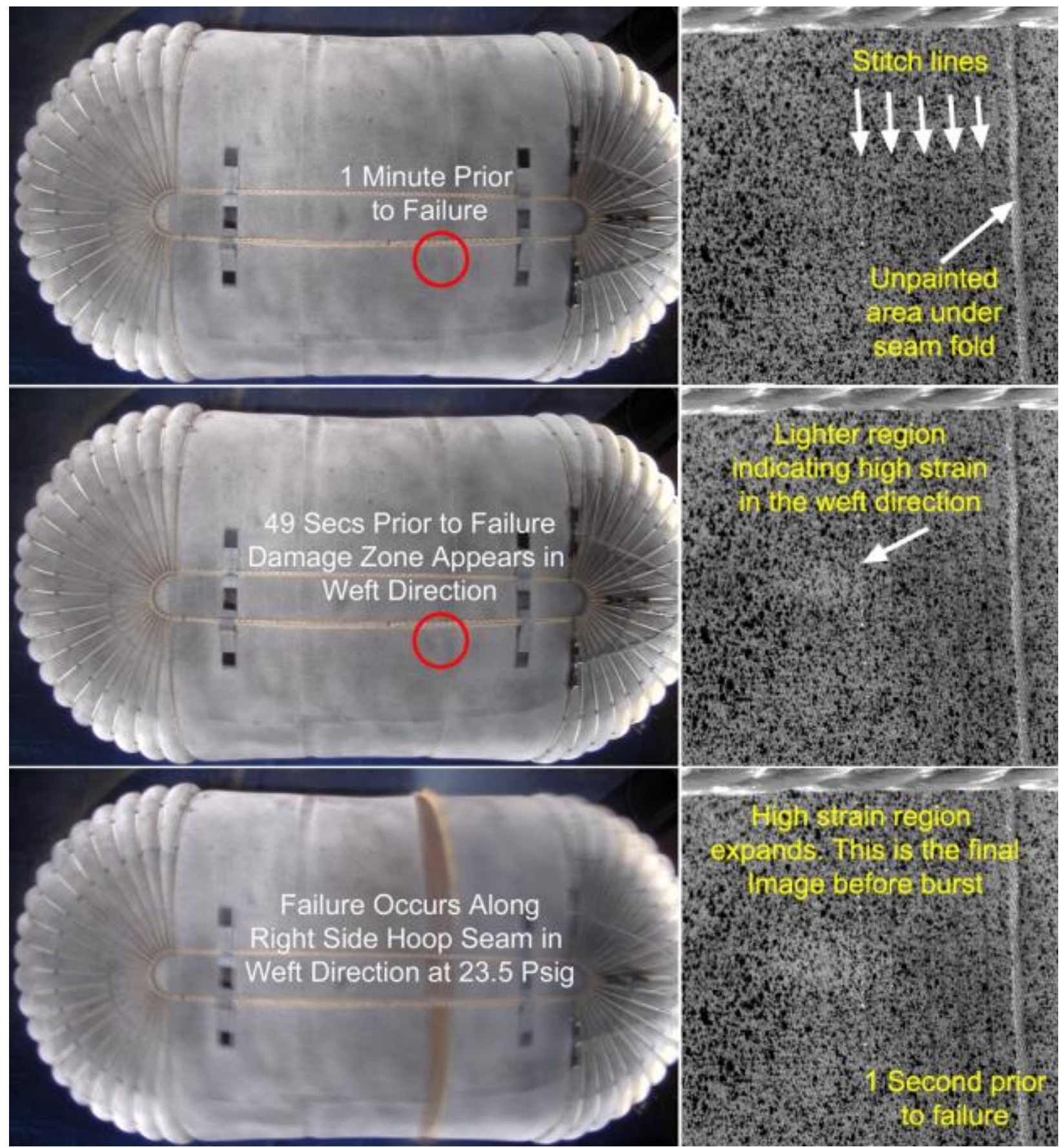

Figure 16. Failure zone before and at burst at 23.5 psig. 


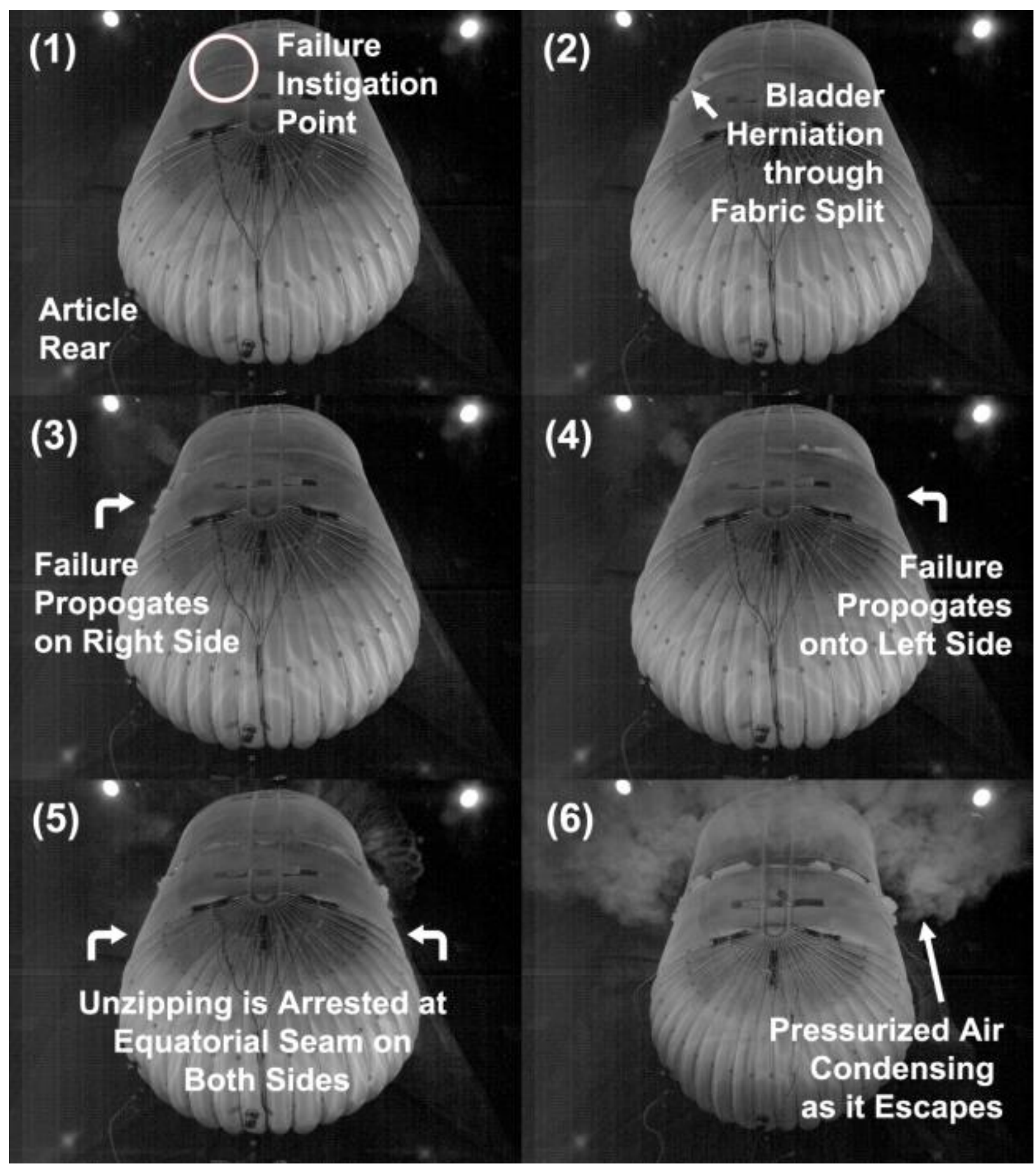

Figure 17. High-speed video of EDU burst at 23.5 psig.

dome hoop seams caused instability in the model, due to their breaking the circular symmetry of the mesh in the domes, and they therefore had to be removed. All other seams are included. The model is freestanding throughout the simulation with no applied boundary conditions. Once full inflation is reached, the symmetric nature of the model keeps it relatively stable in "space". The pressure loads are defined and applied in steps to allow the model to equilibrate at each pressure for data output. The reference state for all test runs of the actual article was 0.5 psig. To achieve a stable model, the FEA article was pre-inflated to 10 psig and then deflated to the initial 0.5 psig before stepping back up in pressure to the desired levels. 


\section{B. Meridional Cordage Load Cell Data}

The 25 load cells were attached to the meridional tendons in the configuration shown in Figure 18, with load cells connected to every other tendon on the bottom side of the EDU (22 total). Three of the meridionals on the rear dome had two load cells attached at opposite ends, to determine if there were load variations over the length of the cords. Each load cell with its connecting hardware and grommet weighed $1.5 \mathrm{lbs}$; therefore the group of 22 load cells was attached on the bottom side to reduce the effect of that mass on the inflation of the article. The load cell data from the test article can be more easily visualized if broken down into six groups of meridionals with the same alignment (same colored meridionals in Figure 19). Each group has two or four mirror symmetric meridionals that form the same angle with respect to the midbody. For example meridionals $1,11,12$, and 22, or 6 , and 17 are grouped together. The average loads in each group, from the test article (solid lines) and the FEA data (dashed lines), are plotted in Figure 19. The first group of meridionals (red) are at the dome-midbody interface, and due to the modeling approach (see section VI-A), of contracting the axial loop during inflation, the FEA loads for those cords did not reach the same load level as the other meridional cords. The average of all meridional loads in the FEA model is within $7 \%$ of the average loads calculated from simple Pressure*Area estimations (represented by ' $\mathrm{X}$ 's in Figure 19), across all pressures. The EDU meridional cords however display higher loads versus the FEA data and P*A estimations by an average of $28 \%$ (excluding the first group) at $23.5 \mathrm{psig}$.
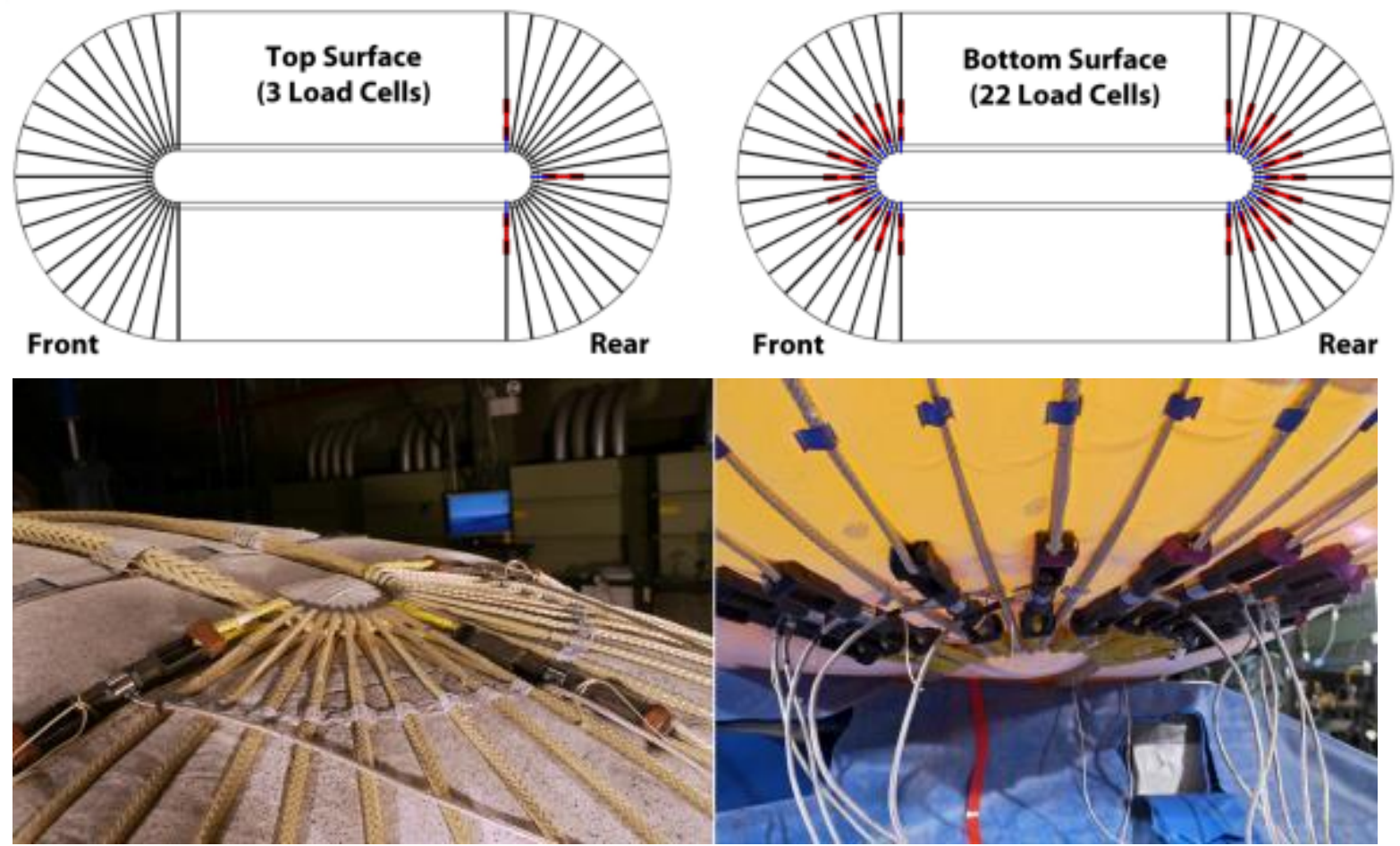

Figure 18. NAIPS EDU load cell configuration.

The higher loads seen in the EDU meridional cords are unexpected given the dimensions and pressure of the EDU were the same as those used in the analytical and FEA models, and are the only global drivers of the meridional loads. The most probable reason for the higher loads is that the stiffer, instrumented meridionals partially offloaded the adjacent uninstrumented meridionals. The stiffness difference in the cords was incorporated into the initial length setting calculations but it is possible the length setting procedure was not performed to the required accuracy. The cords with dual load cells do not directly support this theory however as their loads fall within the same range as the cords with a single load cell, where you would expect higher loads based on the same reasoning. Unfortunately without load readings from the uninstrumented meridionals it is difficult to say whether this is indeed the cause of the higher than expected loads in the instrumented cords. Another theory is that the load cell attachment via threaded yokes (shown in Figure 8) may have allowed a small amount of bending to be induced in the load cell in addition to the axial load as they lay on the curved surface of the article. It is likely however, that bending would have affected the linearity of the curves as the pressure increased. This was also anticipated, thus several load cells were tested prior to the EDU tests to check and confirm that small out-of-plane loads would not affect the 


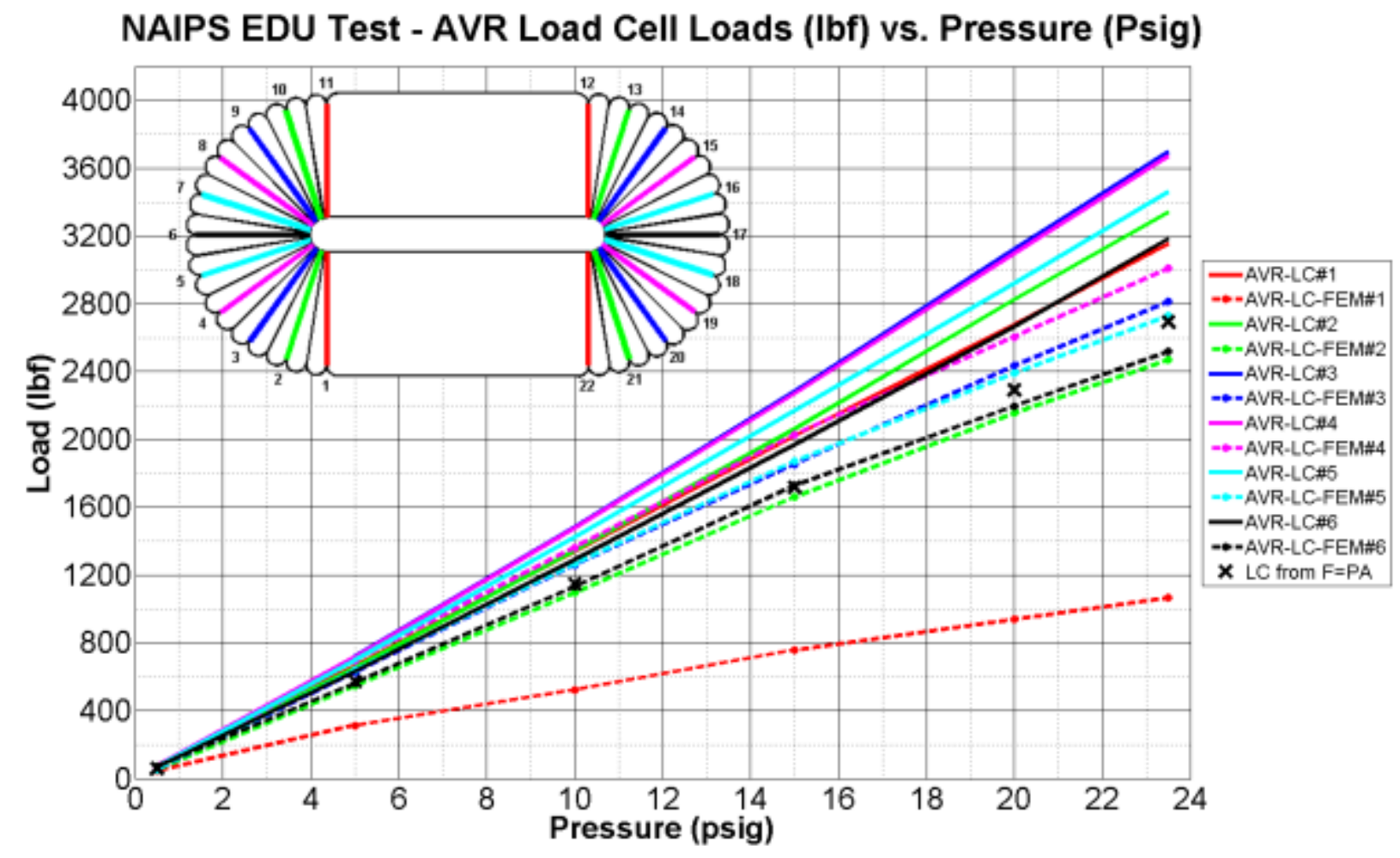

Figure 19. Average meridional cordage loads. Test article (solid) versus FEA (dashed). ' $X$ 's represent
cordage loads calculated from the midbody cross-sectional area multiplied by pressure.

measurement of the axial loads. The load cells were also specifically attached along the flattest portion of the domes. A final hypothesis is that the calibrated conversion gains on the load cells, obtained in a load frame test, were somehow affected or incorrect after attachment to the data acquisition system used during the full-scale test. Currently, a definitive answer has not been reached as to the source of the higher loads in the EDU cordage.

There are also slight differences in the load distribution in the meridionals between the test article and the FEA model. In the test article, the highest meridional loads are in the \pm 45 degree directions and the loads fan out and decrease toward the middle (cords 6 and 17) and toward the dome-midbody interfaces. In the FEA model, a similar distribution is shifted slightly towards the middle meridional, where the highest loads are in the \pm 36 degree directions, and the cords at the dome-midbody interface are significantly offloaded. Future iterations of the FEA model will likely have to incorporate the use of thermal turnbuckles in the meridionals in addition to the axial cordage to reduce this effect. The individual meridional loads at the six pressure levels plotted in Figure 19 are illustrated for the test article data in Figure 20, where the colors represent a heat map of the loads for visualization. One load cell signal was lost just above 16 psig and is shown as a dashed line on the rear dome; no obvious damage to that meridional or load cell was evident post-test. The variance between the high and low meridional loads in the test article remains below 15\% throughout the test, whereas in the FEA model, the variance is slightly larger at $20 \%$ and as much as $30 \%$ at $0.5 \mathrm{psig}$ where the model is less stable (excluding the outlier cords at the dome-midbody interface).

The loads for the three meridionals with two load cells attached can be seen in Figure 20 at the bottom dome of each EDU plot where there are three additional load values, and dual colored meridionals shown. A sizable variance in the load in the two sensors was observed for two of the three meridionals. The meridional at the dome-midbody interface at the bottom right of each EDU plot had the lowest variance in load at 1 to $3 \%$. The middle meridional and the left-side meridionals with dual sensors had variances of 16 to $19 \%$ and 10 to $12 \%$, respectively, over the entire pressurization range. Some small variance in the sensors was expected due to the resolution of the 10Kip load cells; however the large variances seen in two of the three cords was unexpected. The percentage difference between the top and bottom sensors remained steady throughout the test, which suggests the variance is systemic and based in the sensor rather than evidence of an actual phenomena in the article. However it complicates the interpretation of 
variances in the other load cell readings, as they are of similar order to the differences seen along a single meridional. The load cells will be reevaluated for accuracy and mounting approach for any future test articles that incorporate them.
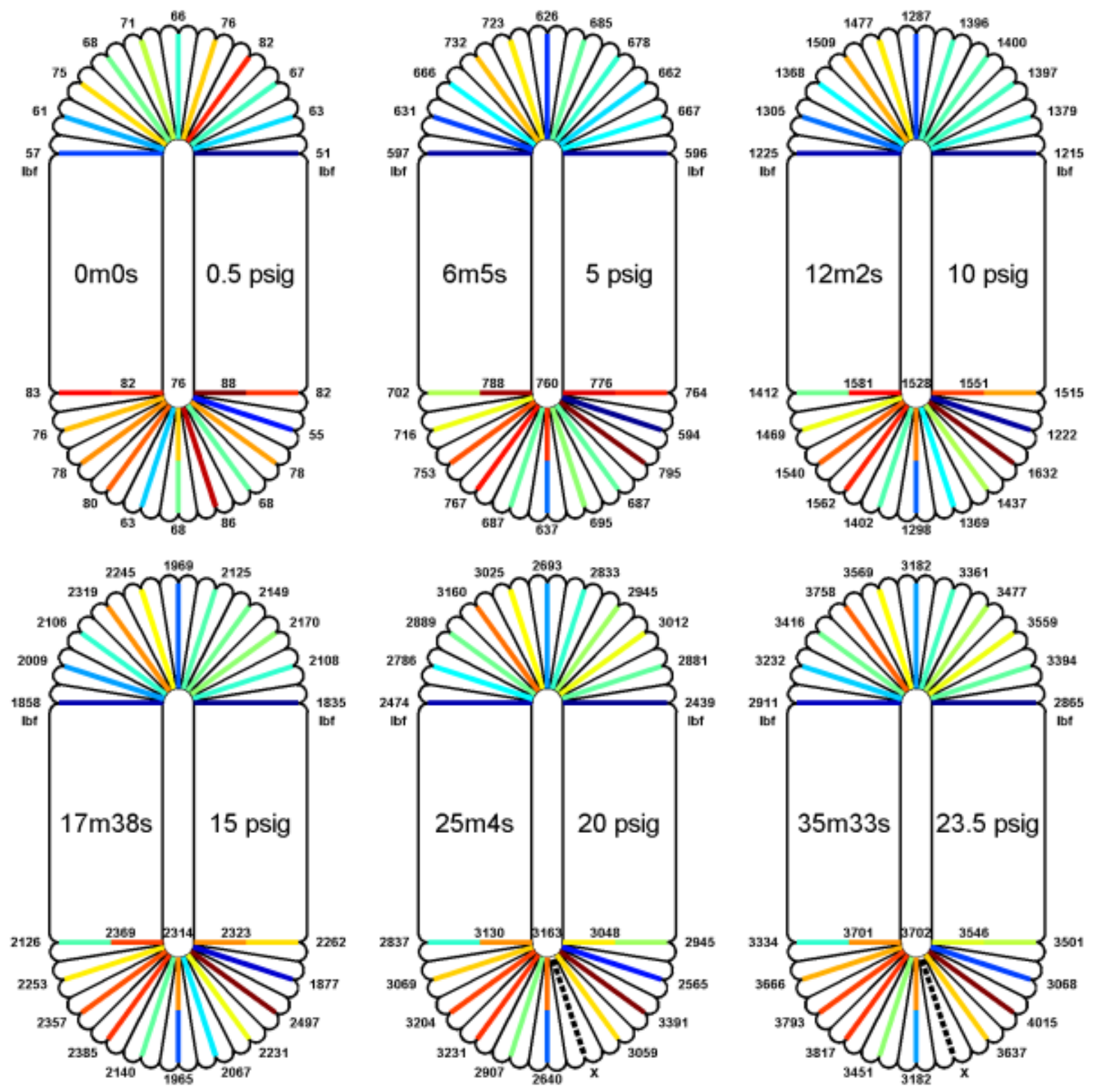

Figure 20. Meridional cordage loads for article pressures of 0.5 to 23.5 psig during final run to burst. Colors represent heat map of loads in the meridionals from blue (low) to red (high).

\section{Fabric Strains from Photogrammetry Data}

The second major component of the comparison between the test article data and the FEA model were the principle strains in the dome and midbody fabrics. The eight photogrammetry systems (abbreviated 'SYS' in the data reduction) provided a large data set of full-field strain measurements that covered approximately half the surface area of the article. The stereoscopic cameras were setup to frame overlapping areas from just below the equator to the top of the EDU, from the right side of the midbody (starting with SYS-1), around the front dome and 
down the left side of the midbody (to SYS-7). A higher resolution, 29 MP system was placed overhead (SYS-8) that overlapped the other seven horizontal systems (shown in Figures 14 and 15). The fabric in the observed areas was spray painted with a speckle pattern that the photogrammetry systems use to track displacements and strains. Photogrammetry strain results must be analyzed carefully, as data at the very edges of the frame, and data in areas of the article where the pattern becomes obscured or altered, can produce erroneous strains. Measuring strain directly on the stitched seams via photogrammetry is untrustworthy due to the movement of the stitches during inflation (twisting and subduction of the thread) that can alter the pattern and disrupt the accurate tracking of those areas. Due to these issues and the size of the data set, a number of interrogation lines (labeled in Figure 21) were used to compare data from the photogrammetry systems to the FEA model.

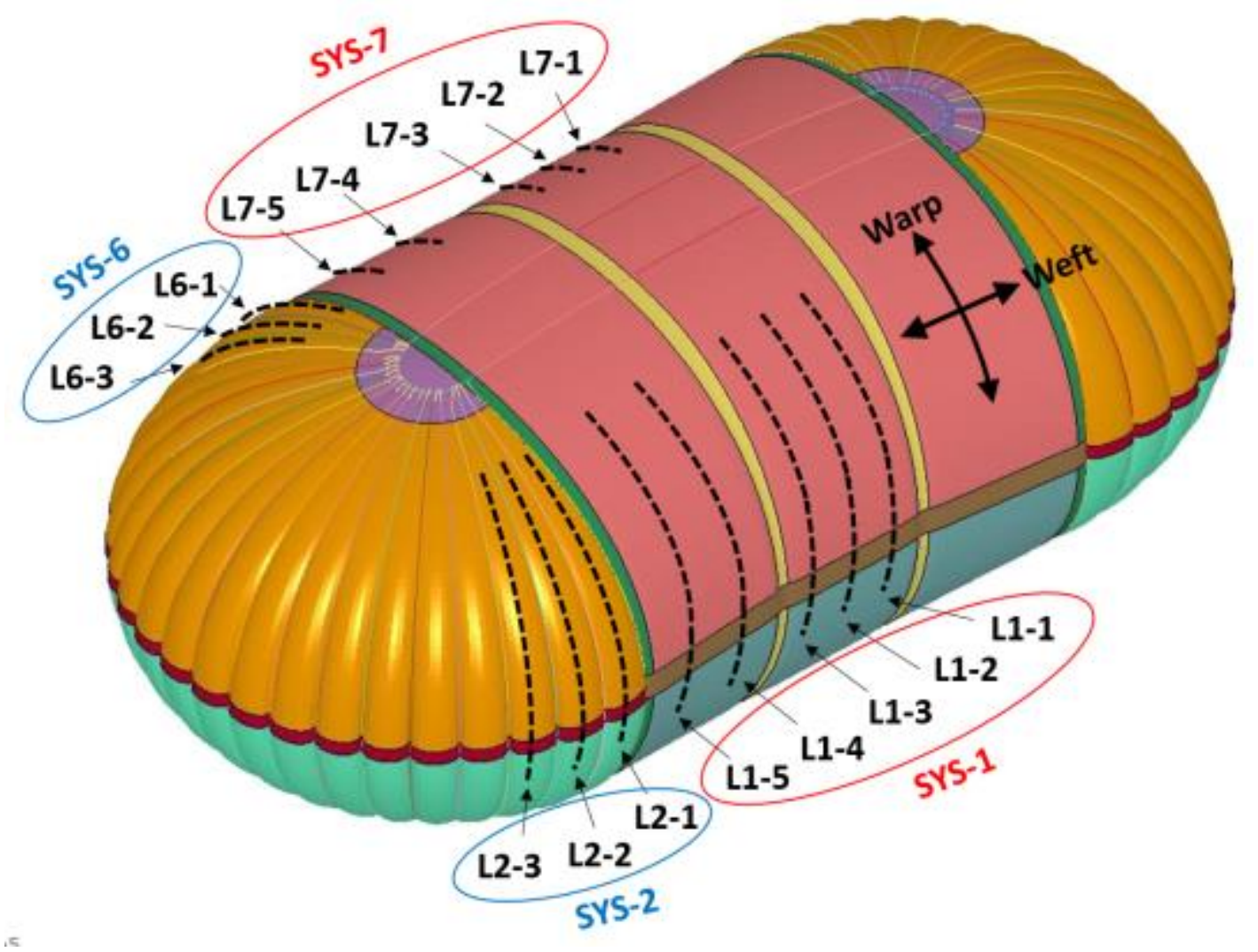

Figure 21. Interrogation lines (dashed) for data comparison between FEA and photogrammetry systems, SYS-1, SYS-2, SYS-6 and SYS-7.

The typical method of photogrammetry data reduction, using a fitted plane or cylindrical surface through the data points was not feasible due to the unusual shape and curvature of the EDU. Therefore, a MATLAB script was written to calculate the warp (e1) and weft (e2) direction strains along the selected interrogation lines on the surface of the midbody and domes. The raw nodal displacement data were used, which allows the change in curvature from point to point to be accounted for. The primary areas of interest were in the lobes nearest the dome-midbody interface and the midbody, particularly in the axial weft direction. Comparisons of the average warp and weft strains for all lines were made at pressures of 5, 10, 15, 20 and 23.5 psig and are plotted in Figures 22 to 25. The FEA strains above $0.5 \mathrm{psig}$ are referenced (or zeroed) to the $0.5 \mathrm{psig}$ model state, as that was the initial state used in the tests. The photogrammetry strains therefore read as zero at $0.5 \mathrm{psig}$ in the plots. The warp direction runs from the top of the article to the bottom, and the weft direction follows the equator or axial direction along and around the article. The strains are consistent between the symmetric, SYS-1 and SYS-7 lines in the midbody and the SYS-2 and SYS-6 lines in the dome.

The FEA results for the midbody warp direction (Figures 22 and 23) display a consistent and slightly increasing strain offset from 0.004 to 0.007 on both sides. This suggests the model is less stiff under the same pressure loading than the test article. As discussed in section IV-B, the load versus strain data for both fabrics, were based on tests of 


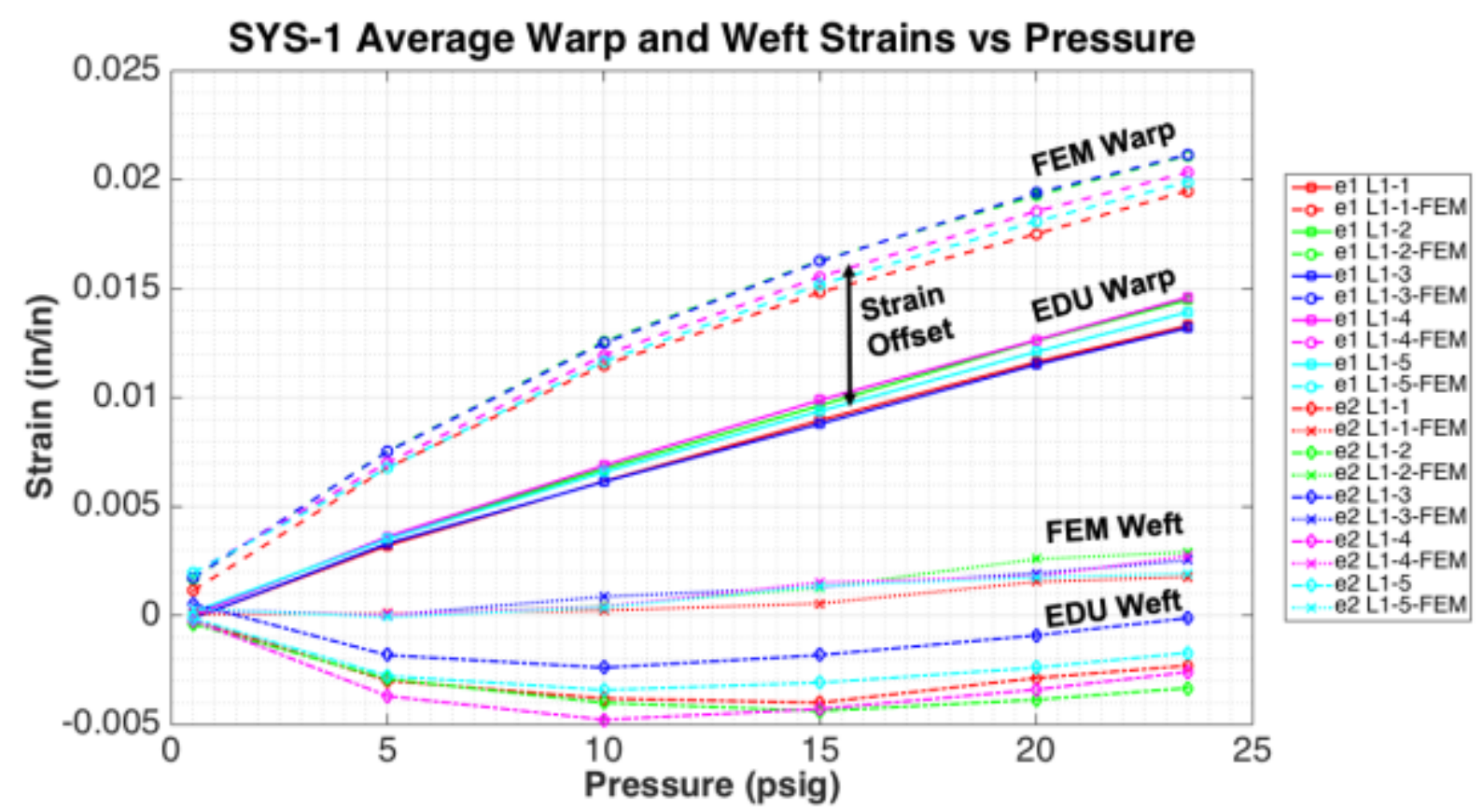

Figure 22. Right side midbody (SYS-1) interrogation lines warp and weft strains vs. pressure.

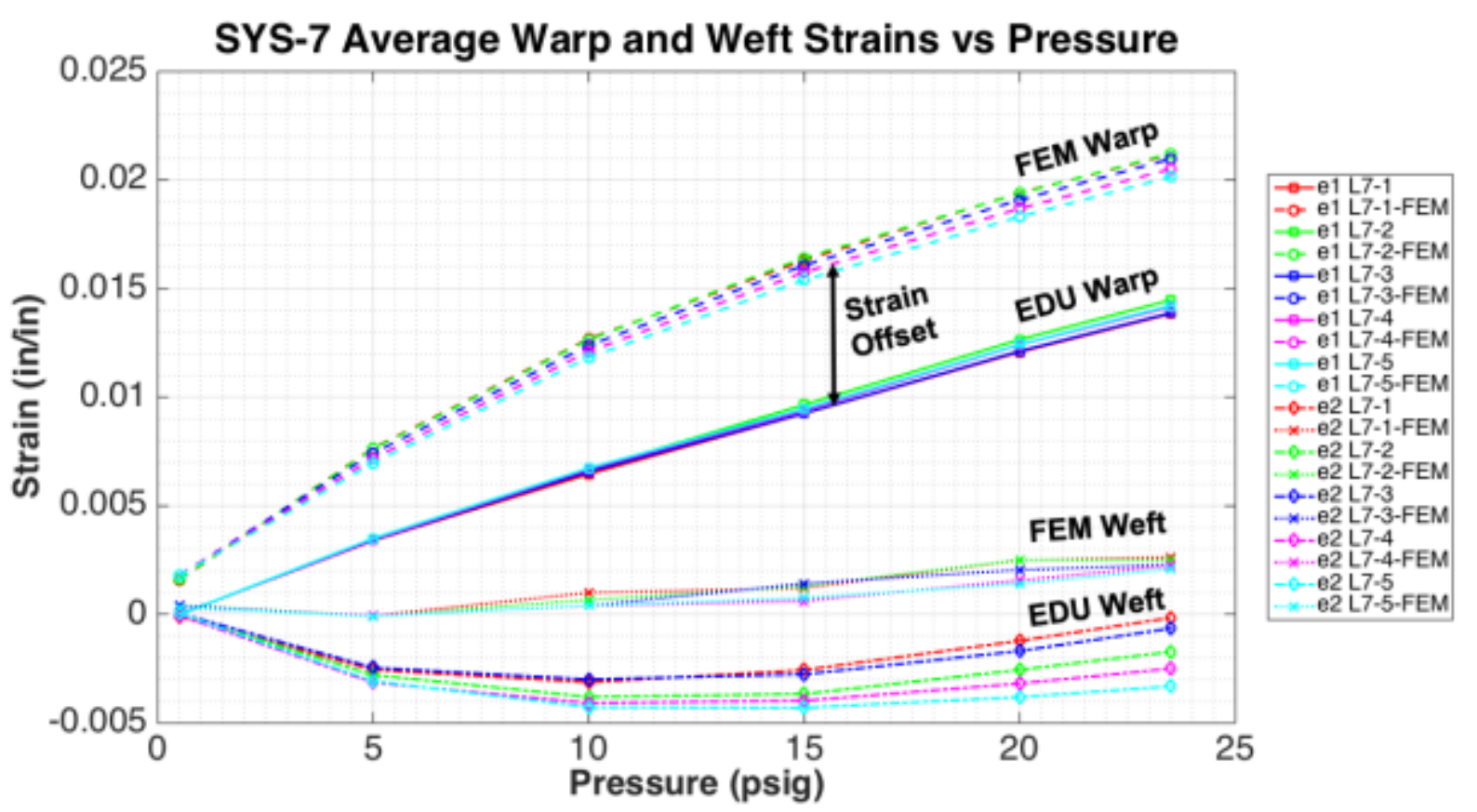

Figure 23. Left side midbody (SYS-7) interrogation lines warp and weft strains vs. pressure.

preconditioned material, but the preconditioning load levels were based on the pristine material behavior. It is likely that preconditioning to a higher load level, in accordance with the multiple pressurization cycles performed, would produce a stiffer load versus strain curve. This would reduce the strains seen in the FEA model at the same pressures. The stiffness of the FEA midbody seams may also not be identical to the test article, as the stitching and Dacron buffer layer are not included. Finally, as noted in VI-B, the meridional cords (and by extension the axial cords) were not as highly loaded as the test article and therefore the fabric in the FEA model would have to support higher loads than the fabric in the EDU, resulting in higher strains. The weft direction results in the midbody are slightly misleading as the FEA model cannot support compressive loads in the fabric and it has no capability 
currently to model the wrinkling that occurs. The test article was pre-inflated to $0.5 \mathrm{psig}$, and as pressurization is increased, micro-wrinkling occurs along the length of the midbody as designed, which is captured by the photogrammetry systems. In addition to the previously mentioned preconditioning issue with the fabric models, the wrinkling / unwrinkling behavior is a nonlinear effect and the strain offset (and wrinkling) that occurs reduces as the pressure increases.

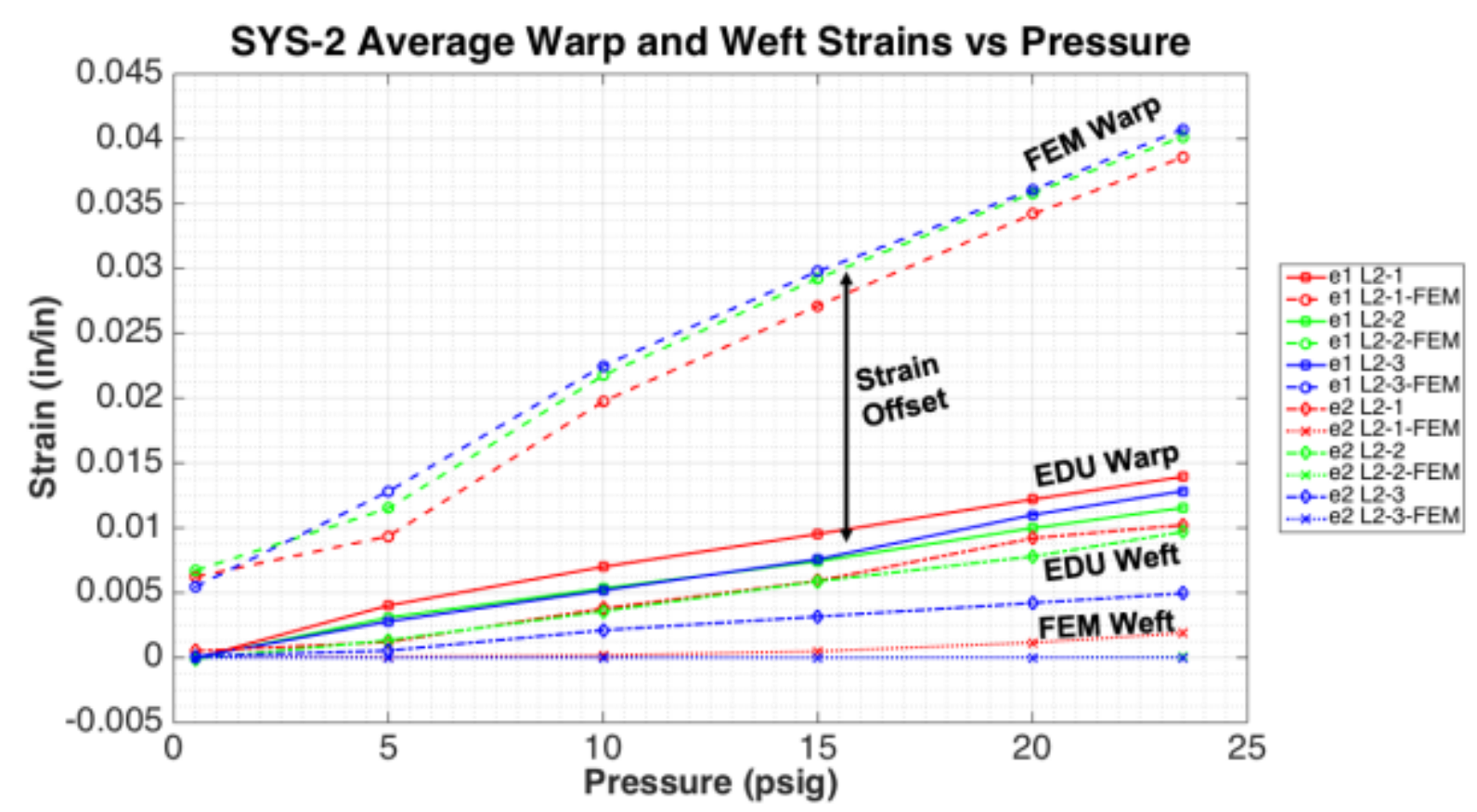

Figure 24. Right side front dome (SYS-2) interrogation lines warp and weft strains vs. pressure.

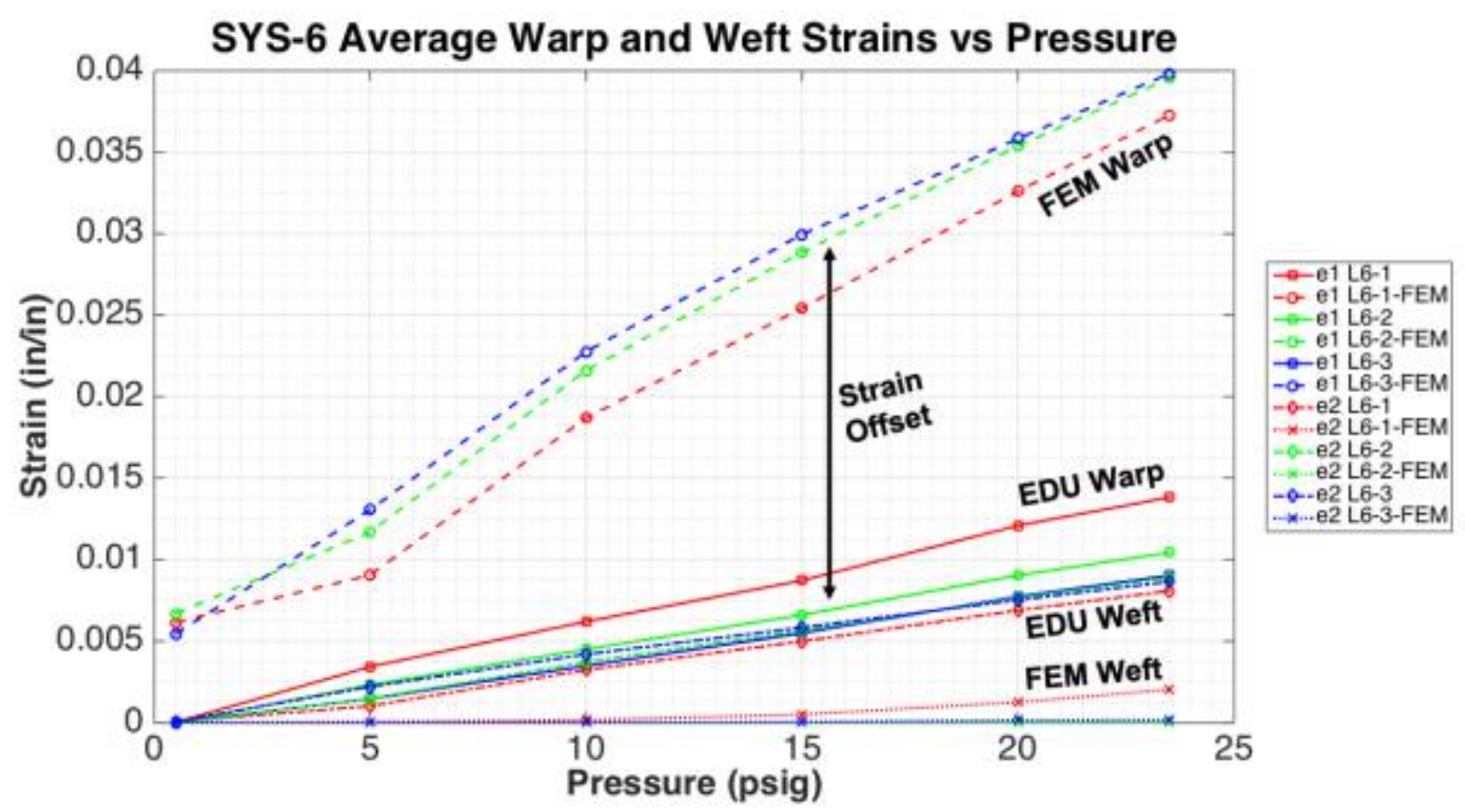

Figure 25. Left side front dome (SYS-6) interrogation lines warp and weft strains vs. pressure. 
The FEA results for the dome fabric (Figures 24 and 25) show a large discrepancy with the photogrammetry data from the test article. High warp direction strains of up to 0.040 at 23.5 psig are three to four times higher than those seen in the test article. The dome fabric warp direction is aligned with the meridional cords, which are underloaded in the FEA model. Further, the three lines interrogated on each side of the dome are on the three lobes closest to the dome-midbody interface. The meridionals in the FEA model near the dome-midbody interface are the most severely offloaded due to the axial cordage tensioning / shortening approach, thus the fabric in that direction would be expected to take up the additional load, which is evident in the results. The warp strains in the test article remain below 0.015 , signifying the meridional cordage in the EDU was properly offloading the fabric. As expected, the warp direction strains in both the midbody and the first lobe of the dome are almost identical due to strain compatibility. The warp strains in the lobes are also observed to decrease for the lobes further from the domemidbody interface, due to offloading from the meridional cords. The weft direction strains in the FEA model stay essentially at zero throughout the loading, which is unexpected. Due to the lobing between cords, a small amount of load is expected that is proportional to the radius of the lobe. The test article displays weft strains of 0.005 to 0.010 , which correlates to a cross load of 25 to $50 \mathrm{lbs} /$ in (see Figure 12) as expected. It is possible the high loading in the lobe's warp direction, in a manner analogous to the midbody, is causing the equivalent of micro-wrinkling, which the FEA model returns as zero strain due to its 'no compression' setting.

The failure location on the inside edge of the second midbody hoop seam was not seen in the FEA model as a high strain area. The failure appears to be a local point failure caused by a high stress zone that then propagated along the seam. The photogrammetry strain data for the overhead SYS-8 were analyzed and correlated to the video to pinpoint the location of the failure. Figure 26 details the exact location of the failure zone and the approximate strain in the midbody warp and weft directions. The $4.7 \%$ strain in the weft direction is beyond the $3.5 \%$ ultimate strain of the fabric in that direction and is considered approximate due to the breakdown of the speckle pattern at the failure zone. This correlates to the appearance of the failure zone 49 seconds prior to this final frame before burst. When the zone first appears there is a jump from the nominal $1.5 \%$ to $2 \%$ strain. Within 10 seconds the weft fabric reaches 3.2\% strain and the speckle pattern starts to breakdown. 3.5\% is crossed 24 seconds after that. Single fiber failures cause the load to transfer to adjacent weft fibers and a cascade failure unzips the article approximately 16 to 40 seconds after the first weft fiber(s) breaks.

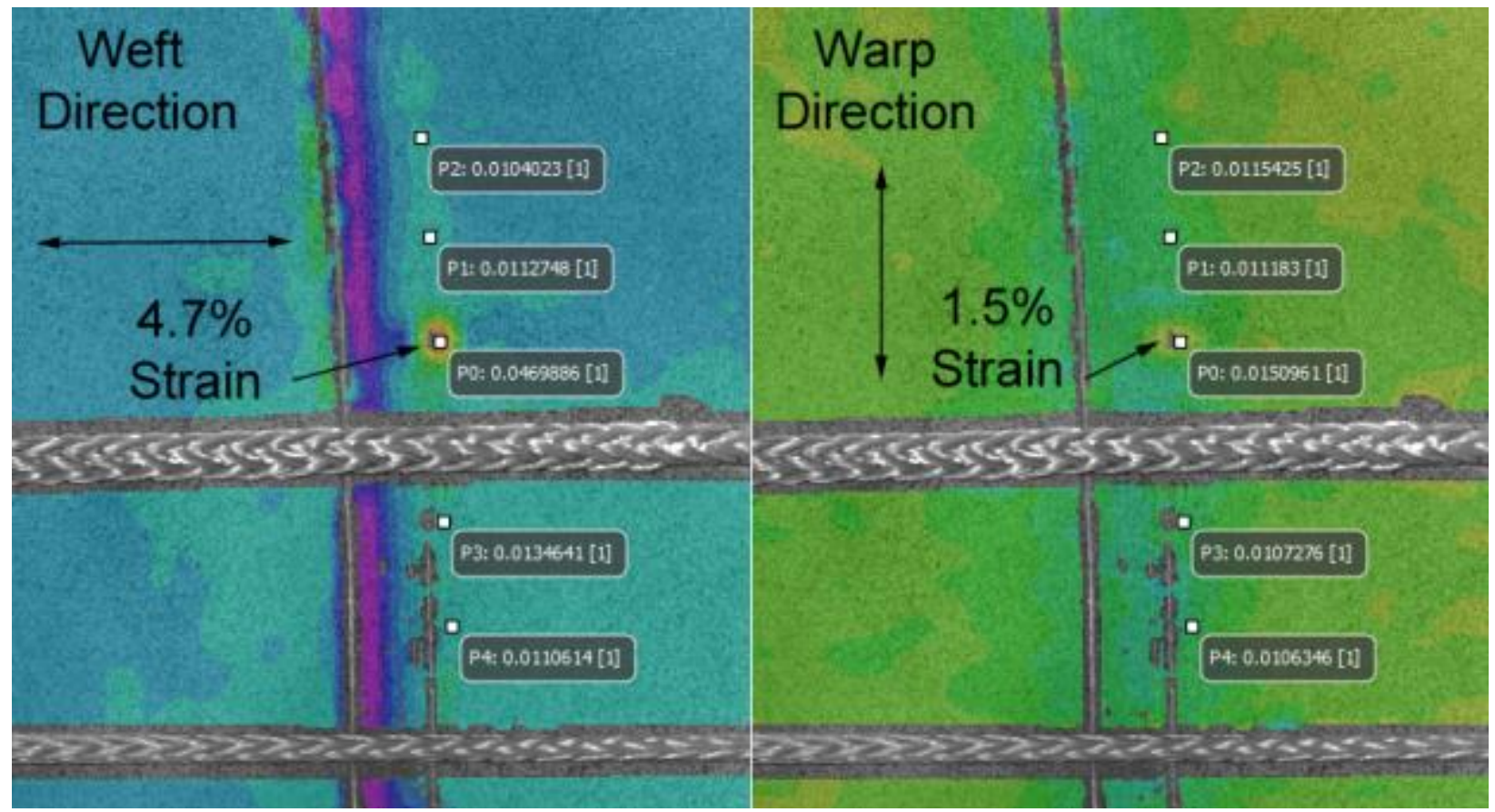

Figure 26. Right side top failure location at 23.5 psig. High strain in weft direction at failure point. 


\section{Lessons Learned and Recommended Updates to EDU and FEA Model}

The design, fabrication and testing of the first prototype NAIPS inflatable airlock EDU succeeded in its primary objectives of validating the areas of low stress in the article and determining the location and mechanism of failure for the current iteration of the design. The results of the EDU test and the comparison of the strains and cordage loads with FEA identified areas for improvement and modification in both the inflatable article design and the FEA model. The lessons learned from the test can be broken down into those relating to the design and manufacture of the article and those associated with the FEA modeling approach.

\section{A. Lessons learned and modifications to the NAIPS EDU}

Due to the aggressive schedule of the MASH program, materials selection and testing, and manufacturing and modeling approaches were still being developed during the construction and preparation for testing of the first EDU article. The original program plan was to test the first EDU as a pathfinder, to gauge what works and how the models, fabrication, and testing could be improved for several follow on articles that would be evolutions of the design. Unfortunately, the program was cancelled as part of several programmatic cutbacks at NASA and the additional articles were not manufactured. The first article led to the following list that encompasses areas for future work.

The highly biased midbody fabric, although well suited to the load distribution in the article, was difficult to handle without causing windowing and weft fiber shifting, and it didn't produce a structurally efficient stitch. These combined effects likely led to the early failure of the EDU. Future articles would consider low-bias or plain weave fabrics throughout to address this. These fabrics allow an increased seam efficiency and lower chance of a local failure due to handling and manufacture, and although less mass optimal on paper, can produce a more efficient approach overall.

- The EDU required ten large structural seams to attach the fabric sections together. Future iterations would seek to further offload the fabric to allow a reduction in the size and number of the seams. In general, as the strength (and thickness) of the fabric increases it becomes more challenging to produce an efficient seam. The seam becomes less packageable with a higher probability of damage due to that packaging, and increases the requirements on the manufacturer and sewing machine to form the larger seams.

- For the fabrics chosen for the next design iteration, the stitched seams should be carefully evaluated under load to understand the local strain behavior and produce a structurally efficient seam.

- To reduce the loads in the midbody fabric, cords could be added around the midbody in the next iteration of the article to act as the primary hoop load restraint layer. Additional fabric added in the midbody axial direction would form lobes between the hoop cordage in a similar fashion to the lobed end domes, reducing the variability in weft direction loads that increased towards the top and bottom of the article and reducing the load requirements on the midbody hoop seams.

- To ensure the load is transferred to the cordage, pleated fabric could also be added around the equator of the article. As the article inflates, loads in the warp direction of the lobes (i.e., in line with the cords) would then be guaranteed to only be taken up by the cordage.

- The NAIPS EDU used large diameter cordage to distribute and carry the loads, in part due to oversizing and in part due to the relatively small number of lobes ( 20 on each end). The next iteration of EDU could increase the number of lobes in the end domes, reducing the required diameter of the meridional cords and reducing the load in the fabric. Cords with smaller diameters and fewer fibers tend to have lower variability in mechanical behavior and are less stiff than the thicker cords used in the EDU, which can help reduce the sensitivity to exact length setting and produce a more even load distribution.

- The cords were indexed to the fabric via eight loops per meridional and four large loops per axial loop. Additional indexing is needed at the meridional-to-axial loop connections to better maintain the positioning of the meridionals around the ends of the loops during initial load-up.

- The axial loop construction approach along with the natural variability in the high strength 1-inch Vectran cordage resulted in a higher than desired chance for variation in the set length, which affects the load-up of the meridionals and fabric in turn. It is possible that multiple smaller diameter cords could be used to form the axial loops, but it would be challenging to ensure that not only the lengths were set correctly but that all the cords remain in their original location in the bundle during pressurization, so as to evenly load all of them. To reduce the variability in the current single cordage loops, the preconditioned and length set meridionals could be pre-attached to the axial cords, and the axial cords would then be preconditioned and length set in the 1.2MKip test frame with the attached cordage suspended off to one side. 
- An entirely separate additional axial loop could also be added on both top and bottom to add redundancy to the primary load bearing members, reducing the likelihood of a catastrophic failure. This idea was discussed in Doggett et al .

- It was noted during examination of the EDU after the failure that the bladder material, which also requires heat sealing individual pieces together, had a seam that ran directly underneath the midbody seam that failed. Although it is unlikely this had a major impact on the failure and herniation of the bladder through the fabric, the bladder and fabric seams should be offset from one another in future articles.

\section{B. Lessons learned and modifications to the FEA Model}

The FEA modeling of the NAIPS EDU is an extremely challenging analysis problem due to the indeterminacy of the structure during initial inflation combined with the contact interactions of the cordage and fabric, and the specific non-linear phenomena of a hierarchical softgoods structure. The EDU test was the first chance to collect a detailed data set for comparison to the FEA model. The results illustrate that there is still significant work to be done, not only in improving the FEA model but also on the material testing that supports that model, which would feed into comparisons with future iterations of the NAIPS design. Accurate material characterization, including the effects of preloading, stitching and braiding, and accurate instrumentation and sensors to provide the bridge between the component material models and the FEA model for verification and validation are critical. The following list describes some of the areas for future FEA work.

- The meridional cords in the model should have individual thermal 'turn-buckle' elements in addition to the ones used in the axial cordage loops to correctly set the initial lengths. The contraction of the cords at low pressure causes analytical instability due to large fabric shell deflections and maintaining contact definitions. The current scheme of inflating to a stable configuration, then contracting all the cords followed by reducing the pressure back to a nominal initial level to start the main analysis appears to be the best approach, but needs to be verified.

- The contraction of the cordage elements would need to be done iteratively to reach a desired length in each cord at a set pressure. The current approach sets the axial cordage length based on reaching a required resultant load in two of the meridionals that are aligned with the axial direction. Due to the differences in the meridional cordage loads, as detailed in Section VI-B, adjusting for a set length rather than a set load would be considered in the next iteration of the model.

- The mid-dome seams in the FEA model had to be removed as they caused instability in the model, due to their breaking the circular symmetry of the mesh in the domes. A different meshing approach is needed for future model iterations to ensure all seams are included. Tetrahedral elements with a higher mesh density at the seam are possibilities, but would need to be validated with a simpler model initially.

- As mentioned in (A), the FEA model is only as good as the material data it uses; therefore further testing is needed on the cordage, fabric and seams, but especially on the distribution of stresses in the discontinuous regions around the seams. If the analytical model only predicts the behavior of the base fabric and cordage without an accurate seam representation then there is the danger of getting an unforeseen failure.

\section{Conclusions}

A novel Non-axisymmetric Inflatable Pressure Structure (NAIPS) has recently been developed and tested under the multi-center MASH program at NASA. The NAIPS design provides a highly compactable and lightweight option for packaging large pressurized volumes for space exploration applications. Low stress zones designed into the structure allow the integration of a flexible linear seal that can replace a typical heavy and bulky heritage hatch. To demonstrate the feasibility of the NAIPS design and evaluate the fabrication and analytical modeling of the geometry, a first generation, full-scale EDU was recently tested at the COLTS Facility at LaRC. The test was the culmination of constructing and assessing a series of sub-scale models, performing material and stitch testing on the fabric and cordage, and designing and fabricating the finished article. The test produced a highly comprehensive data set from the final run to burst at $23.5 \mathrm{psig}$, which included pressure, meridional cordage loads, full-field strain measurement over a half of the surface and real-time and high-speed video of the failure. The failure occurred in the highly biased midbody fabric near the second midbody hoop seam, likely due to a local stress concentration in the weft fibers. The cordage loads and strain data were compared to FEA and although the model provided excellent insight into the initial design of the EDU article, further development is required to emulate the cord shortening used 
in the EDU and accurately model the local seam behavior. Results of the comparison were presented and suggestions for future test article and FEA model modifications were suggested.

\section{Acknowledgements}

The full-scale NAIPS EDU test was the result of the combined efforts of three NASA centers and a large and dedicated team of engineers and technicians without whom this effort wouldn't have been successful. The authors would like to thank the softgoods lab at JSC, led by Mark Schaefbauer, for their expertise and execution in manufacturing the NAIPS EDU restraint layer shell and bladder. We would also like to thank the team of personnel that aided in the setup and implementation of the full-scale test including; COLTS personnel - Scott Runnells, Jim Gaspar, Carlito Barnes, Steve Nevins and William Wilkerson; data acquisition - Scott Simmons, Matt Skerl and Larry Arnold, camera and light systems - Paul Bagby, Sandie Gibbs and Greg Dean, and photogrammetry - Michael McNeil, Nate Gardner and Will Johnston. Finally, the authors would like to thank the other members of the MASH team who aided throughout including, Dave Moore, Clarence Stanfield, Keith Bird, Nathaniel Mesick, Fred Whitehead, Tom Walker and Tim Roach.

\section{References}

${ }^{1}$ Doggett, W. R., Jones, T. C., Watson, J. J., Warren, J. E., Makino, A., Selig, M., and Mikulas, M. M., "Non-Axisymmetric Inflatable Pressure Structure (NAIPS) Concept that Enables Mass Efficient Packageable Pressure Vessels with Openings," 3rd AIAA Spacecraft Structures Conference, 2016 AIAA SciTech Forum and Exposition, AIAA Paper 2016-1475.

${ }^{2}$ Taylor, G. L., "On the Shapes of Parachutes," (Paper written for the Advisory Committee on Aeronautics), in The Scientific Papers of G.I. Taylor (1963) (edited by G.K. Batchelor), Vol. 3, Cambridge University Press, Cambridge, England, originally written 1919.

${ }^{3}$ Mikulas, M. M., Jr., "Behavior of Double Curved Partly Wrinkled Membrane Structures Formed from an Initially Flat Membrane,” Ph.D. Dissertation, Virginia Polytechnic Institute, Blacksburg, VA, June 1970.

${ }^{4}$ Burggraf, O., "Analytical Design for Optimum Filamentary Pressure Vessels," AIAA Launch and Space Vehicle Shell Structures Conference, Palm Springs, CA, AIAA Paper 2914, 1963.

${ }^{5}$ Mikulas, M. M., and Bohon, H. L., "Development Status of Attached Inflatable Decelerators," Journal of Spacecraft and Rockets, Vol. 6, 1969.

${ }^{6}$ Willis, C. M., and Mikulas, M. M., Jr., "Static Structural Tests of a 1.5-Meter-Diameter, Fabric Attached Inflatable Decelerator," NASA TN D-6929, NASA Langley Research Center, Hampton, VA, 1972.

${ }^{7}$ Lennon, A., and de Jong, M., "Geometric Analysis for Inflatable Space Habitats," International Conference on Textile Composites and Inflatable Structures, Structural Membranes 2007, E. Oñate, and B. Kröplin, (Eds) CIMNE, Barcelona, Spain, 2007.

${ }^{8}$ Lennon, A., and de Jong, M., "Benefits and Limitations of Analysis in the Design of Pressure Restraint Layers for Inflatable Space Habitats," Fourth European Workshop on Inflatable Space Structures ESTEC, Noordwijk, Netherlands; 16-18 June 2008. ${ }^{9}$ Shariff, K., Schaefbauer, M., Doggett, W. R., Warren, J., and Jones, T. C., "Inflatable Airlock: Seaming Techniques of Highly Loaded Fabrics," $4^{\text {th }}$ AIAA Spacecraft Structures Conference, AIAA SciTech Forum and Exposition, Gaylord, TX, 2017.

${ }^{10}$ ASTM Standard D5034-09 (Reapproved 2013), "Standard Test Method for Breaking Strength and Elongation of Textile Fabrics (Grab Test),” ASTM International, West Conshohocken, PA, 2013. 